University of Warwick institutional repository: http://go.warwick.ac.uk/wrap This paper is made available online in accordance with publisher policies. Please scroll down to view the document itself. Please refer to the repository record for this item and our policy information available from the repository home page for further information.

To see the final version of this paper please visit the publisher's website. Access to the published version may require a subscription.

Author(s): Estes, Zachary; Jones, Lara L.

Article Title: Integrative priming occurs rapidly and uncontrollably during lexical processing.

Year of publication: 2009

Link to published version: http://dx.doi.org/10.1037/a0014677

Publisher statement: 'This article may not exactly replicate the final version published in the APA journal. It is not the copy of record.' 
Running head: INTEGRATIVE PRIMING

Estes, Z. \& Jones, L. L. (2009). Integrative Priming Occurs Rapidly and Uncontrollably during Lexical Processing. Journal of Experimental Psychology: General, 138, 112-130.

Address correspondence to:

Zachary Estes

Department of Psychology

University of Warwick

Coventry CV4 7AL

United Kingdom

E-mail: z.estes@warwick.ac.uk

Lara L. Jones

Department of Psychology

Francis Marion University

P.O. Box 100547

Florence, SC 29501

United States

E-mail: ljones@fmarion.edu 


\begin{abstract}
Lexical priming, whereby a prime word facilitates recognition of a related target word (e.g., nurse $\rightarrow$ doctor), is typically attributed to association strength, semantic similarity, or compound familiarity. Here we demonstrate a novel type of lexical priming that occurs among unassociated, dissimilar, and unfamiliar concepts (e.g., horse $\rightarrow$ doctor). Specifically, integrative priming occurs when a prime word can be easily integrated with a target word to create a unitary representation. Across several manipulations of timing (stimulus onset asynchrony) and list context (relatedness proportion), lexical decisions for the target word were facilitated when it could be integrated with the prime word. Moreover, integrative priming was dissociated from both associative priming and semantic priming, but was comparable in terms of both prevalence (across participants) and magnitude (within-participants). This observation of integrative priming challenges current models of lexical priming, such as spreading activation, distributed representation, expectancy, episodic retrieval, and compound cue models. We suggest that integrative priming may be explained by a role activation model of relational integration.
\end{abstract}

KEYWORDS: associative priming, integrative priming, lexical decision, relational integration, semantic priming, word recognition. 
One of the most robust phenomena of psychology is the lexical priming effect, whereby responding to a target word is facilitated by the prior presentation of a related prime word (for extensive review see Hutchison, 2003; Lucas, 2000; McNamara, 2005; Neely, 1991). In a seminal experiment, Meyer and Schvaneveldt (1971) simultaneously presented two letter strings in a lexical decision task (LDT; i.e., word/nonword judgments). They found that related words (e.g., BREAD - BUTTER) elicited faster lexical decisions than unrelated words (e.g., NURSE BUTTER). Since that classic demonstration (see also Meyer, Schvaneveldt \& Ruddy, 1975; Tweedy, Lapinski \& Schvaneveldt, 1977), researchers have distinguished two broad classes of relation between primes and targets. Association refers to a relation in language use, typically defined as the proportion of participants who produce a given target word (e.g., PEPPER) in response to a cue word (e.g., SALT) in the free association task. Similarity refers to a relation in word meaning, typically defined as the degree of feature overlap between the concepts (e.g., DOG - WOLF). Thus one may distinguish associative priming, which is based on association strength, from semantic priming, which is based on featural similarity (see e.g., Fischler, 1977; Hutchison, 2003; Lucas, 2000; McNamara, 2005; McRae \& Boisvert, 1998; Moss, Ostrin, Tyler \& MarslenWilson, 1995; Shelton \& Martin, 1992; Thompson-Schill, Kurtz \& Gabrieli, 1998). The purpose of the present study is to demonstrate and characterize another source of lexical priming that is independent of both associations and similarity. Namely, we examine the influence of relational integration on lexical processing.

\section{Relational Integration}

By relational integration we mean a process in which individual noun concepts are combined to create a unitary representation. More formally, the first noun (i.e., the modifier) designates a subclass of the second (i.e., the head), such that they jointly refer to a single entity (or class). There are various relations that may be inferred to integrate a pair of concepts. For 
instance, the concepts TABLE and VASE may be integrated via a location relation, as in a vase located on a table. Concepts may also be integrated by relations of causation (e.g., ROPE BURN), composition (e.g., COPPER POT), time (e.g., WINTER HOLIDAY), function (e.g., SKETCH PEN), partonomy (e.g., BEAR PAW), topic (e.g., COWBOY FILM), production (e.g., WIND POWER), and so forth. ${ }^{1}$ Such relational integration is ubiquitous among noun compounds. Gagné (2000) found that approximately $81 \%$ of the noun compounds in the Brown corpus (Kucera \& Francis, 1967) and $86 \%$ in Warren's (1978) sample are understood via relational integration. More concretely, the opening sentence of this paper contains three unique noun compounds, all of which are understood by relational integration (e.g., PRIMING EFFECT, TARGET WORD, PRIME WORD).

Noun compounds serve an important linguistic function: They refer concisely. That is, lengthy references can be reduced by replacing the modifying phrase with a single modifier noun. To illustrate, the noun compound ANIMAL HOSPITAL is much more concise than its explicit phrasal reference, HOSPITAL FOR TREATING ANIMALS. Similarly, a VASE LOCATED ON A TABLE can be denoted by the shorter name TABLE VASE, and a HOLIDAY DURING THE WINTER can be abbreviated as WINTER HOLIDAY. Noun compounds are particularly useful when one instance of the head noun category must be distinguished from another. For example, an ANIMAL HOSPITAL is a specific type of HOSPITAL, namely one that treats ANIMALS. The modifier specifies how the compound concept differs from other members of the head category (see e.g., Clark \& Berman, 1987; Gagné \& Murphy, 1996; Glucksberg \& Estes, 2000; Springer \& Murphy, 1992; Swinney, Love, Walenski, \& Smith, 2007). For instance, ROLLER SKATES have wheels whereas ICE SKATES have blades, and a ROPE BURN is caused by friction whereas most burns are caused by direct heat. Subclassification differentiates integrative relations from other lexical relations known to elicit priming. Henceforth, word pairs separated by an arrow will denote a lexical decision trial (e.g., PRIME $\rightarrow$ TARGET). Although synonymy (e.g., BABY $\rightarrow$ INFANT) and antonymy (e.g., ORDER 
CHAOS) both elicit priming (Hodgson, 1991; McKoon \& Ratcliff, 1995; Perea \& Rosa, 2002), they do not entail subclassification. Nor do associative relations (e.g., SALT $\rightarrow$ PEPPER) or category coordinates (e.g., DOG $\rightarrow$ WOLF) involve subclassification. SALT PEPPER is not a type of PEPPER, nor is DOG WOLF a type of WOLF. Opaque compounds (e.g., HONEYMOON; de Mornay Davies, 1998; Jarema, Busson, Nikolova, Tsapkini, \& Libben, 1999; Libben, Gibson, Yoon, \& Sandra, 2003; Seidenberg, Waters, Sanders, \& Langer, 1984) do have a unitary representation, but they do not entail subclassification; a HONEYMOON is not a subclass of MOONS. Finally, we should reiterate that we are concerned here only with simple noun-noun compounds. Thus, we do not consider instances in which a target noun is integrated with an adjective (e.g., RED $\rightarrow$ APPLE; Smith, Osherson, Rips, \& Keane, 1988) or with a more elaborate context, such as a sentence frame, a text passage or general world knowledge (Forster, 1981; Garrod \& Terras, 2000; Hagoort, Hald, Bastiaansen, \& Petersson, 2004; Hess, Foss, \& Carroll, 1995).

The experiments reported below demonstrate that relational integration occurs routinely during lexical processing, and that its effect is to facilitate word recognition (henceforth integrative priming). In order to determine whether this integrative priming can be explained by any current model of lexical priming, we now review those extant models.

\section{Models of Priming}

Various mechanisms have been proposed to explain lexical priming. These mechanisms vary in terms of the theoretical construct assumed to explain priming: Some models explain lexical priming as a consequence of association strength, others appeal to featural similarity, and still others attribute priming to familiarity. Below we describe several influential models of lexical priming, with particular emphasis on their explanatory constructs. To be clear, we do not intend to present a thorough review of the literature here; excellent reviews are available elsewhere (e.g., Hutchison, 2003; Lucas, 2000; McNamara, 2005; Neely, 1991). Rather, our 
intention is to provide a general and brief overview of the extant models of lexical priming, so that we may assess whether any of them can explain the presumed integrative priming effect.

Spreading activation. The spreading activation model (Anderson, 1983; Collins \& Loftus, 1975; McNamara, 1992a, 1992b, 1994) assumes a localist semantic network in which individual concepts are represented as holistic nodes connected via descriptive links. When a word is heard or read, its node becomes activated, and this activation subsequently spreads to other nodes with which it is associated. By this model, priming occurs when the prime word pre-activates an associated target word. The model thus ascribes priming to association.

Distributed representation. The distributed representation model assumes a semantic network consisting of feature nodes that are distributed across the brain, and it represents concepts as dynamic spatio-temporal patterns of activation (e.g., Becker, Moscovitch, Behrmann, \& Joordens, 1997; Masson, 1995; McRae, de Sa, \& Seidenberg, 1997; Plaut \& Booth, 2000). For example, the word DOG does not activate a single node in the network (as assumed by localist models), but rather activates a set of feature nodes (e.g., four-legged, hairy, barks) that are distributed across brain regions. Priming occurs when the prime and target concepts exhibit overlapping patterns of activation. Thus, the distributed representation model ascribes priming to featural similarity. The more features two concepts have in common, the greater the overlap in neural activation, and hence the greater the lexical priming. A notable exception is the model of Plaut and Booth (2000), who posit an additional word-level representation that may induce priming by association.

Expectancy. According to the expectancy model (Becker, 1980; de Groot, 1984; Fischler \& Bloom, 1979; Neely, 1977; Posner \& Snyder, 1975), the prime word may induce generation of a set of expected target words. For example, CAT may elicit generation of DOG, MOUSE, and 
KITTEN as likely targets. Priming occurs when an expected word appears as a target. The expectancy model therefore ascribes priming to association.

Semantic matching. Semantic matching (a.k.a., coherence checking) refers to a search for a meaningful relation between prime and target (de Groot, 1984; Forster, 1981; Neely, 1977; Neely, Keefe, \& Ross, 1989; Seidenberg et al., 1984). In an LDT, for instance, the presence of a relation between prime and target indicates that the target must be a word, since nonwords are generally unrelated to words. Some investigations of semantic matching have used primes and targets with taxonomic relations (e.g., BIRD $\rightarrow$ ROBIN; Neely, 1977; Neely et al., 1989), whereas others have used associative relations (e.g., STORK $\rightarrow$ BABY; Anaki \& Henik, 2003; Chwilla, Hagoort \& Brown, 1998; de Groot, 1984, 1985; Hutchison, 2002). Thus, priming via semantic matching may be attributed to either similarity or association.

Episodic retrieval. The general premise of an episodic retrieval model is that the target word induces retrieval of the prime word, which may affect responding to that target (Bodner \& Masson, 2001, 2003; Whittlesea \& Jacoby, 1990). Like investigations of semantic matching, episodic retrieval studies tend not to distinguish between associative and semantic relations. Thus, the episodic retrieval model ascribes priming to either similarity or association.

Compound cue. Ratcliff and McKoon (1988) posited that the prime and target concepts “join together to form a compound cue" (p. 385), which is then matched against items in longterm memory. Consequently, the "response to the target will be facilitated to the extent that the prime and target are associated in memory" (McKoon \& Ratcliff, 1992, p. 386; see also Dosher \& Rosedale, 1989). Although McKoon and Ratcliff attributed priming to association, they conceptualized the association between prime and target as the familiarity of the compound. The compound cue model therefore attributes lexical priming to familiarity. 
As described above, the extant models all ascribe lexical priming to associative strength, semantic similarity, or compound familiarity. And indeed, many experiments have demonstrated effects of these three factors on lexical processing. The goal of the present experiments was to investigate whether relational integration also affects lexical processing. Some prior evidence suggests that it might. As Seidenberg and colleagues (1984) noted, "It may be difficult to inhibit recognizing at least some relations between [target] word and [prime] context, because identifying them is a normal and overlearned part of the comprehension process" (p. 324). Given their ubiquity (Gagné, 2000), integrative relations may well be overlearned and difficult to ignore. Indeed, thematic relations affect some basic cognitive processes from which they are theoretically independent, such as similarity (Bassok \& Medin, 1997; Estes, 2003a; Simmons \& Estes, 2008; Wisniewski \& Bassok, 1999) and categorization (Lin \& Murphy, 2001; Murphy, 2001). It therefore seems likely that relational integration would affect lexical processing as well. Moreover, integrative relations could plausibly influence word recognition via basic cognitive mechanisms. For instance, rather than checking whether the target is associatively or semantically related to the prime (see "Semantic matching" above), participants might check whether the target can be integrated easily with the prime. Such a retrospective integration check could clearly affect lexical decisions: If prime and target can be integrated, then the target must be a word, because a prime cannot be integrated with a nonword. Alternatively, relational integration could affect lexical decisions prospectively. Noun concepts are associated with the particular integrative relations that they most frequently instantiate (Gagné \& Shoben, 1997; Storms \& Wisniewski, 2005). For instance, CHOCOLATE frequently instantiates the composition relation (e.g., ChOCOLATE BAR, ChOcolate BunNy, CHOCOLATE CoIn, etc.). During lexical processing, then, a prime word (e.g., CHOCOLATE) could activate the integrative relation that it most frequently instantiates (i.e., composition), and that integrative relation could activate other 
concepts that may plausibly instantiate it. These and other possible mechanisms of integrative priming are considered in greater detail in the General Discussion.

To provide the clearest possible contrast with the extant models, we tested whether integrative priming would occur between concepts that are dissimilar and unassociated and that are unfamiliar as a phrase. Regarding similarity, relational integration is actually more frequent among dissimilar concepts than among similar concepts (Wilkenfeld \& Ward, 2000; Wisniewski, 1996). Because relational integration requires that the two concepts perform complementary roles in a thematic relation (see Jones \& Love, 2007; Wisniewski, 1997; Wisniewski \& Bassok, 1999), integrative compounds tend to consist of semantically dissimilar concepts (Estes, 2003a; Wisniewski \& Love, 1998). For example, the containment relation (e.g., BOX WINE) entails complementary roles of container and contained. Typically, the different roles of a relation are performed by concepts with different features. A liquid, for instance, is more suitable for the contained role than for the container role. Consequently, relational integration is rare among similar concepts.

Contrarily, relational integration appears to be relatively common among associated, familiar compounds. Most phrasal associates (e.g., SPIDER WEB; Hodgson, 1991; Hutchison, 2003; Williams, 1996) are understood via relational integration, and moreover, familiar noun compounds are understood more quickly than novel compounds (Wisniewski \& Murphy, 2005). These findings suggest that integrative priming may occur often among associated, familiar concepts. In such cases, however, it is impossible to determine whether facilitation of the target word is due to relational integration, association strength, or compound familiarity. If relational integration facilitates lexical processing, then concepts that are dissimilar, unassociated, and unfamiliar (e.g., DONKEY PARADE) should also exhibit lexical priming. Such a result would not be explicable via any of the extant models of lexical priming. 
Preliminary Evidence. Coolen, van Jaarsveld, and Schreuder (1991) provided preliminary evidence that relational integration affects lexical processing. In one experiment, they preceded target words with a prime word that produced either a highly integrative or a less integrative compound. For instance, the target word MARKET followed either LEMON or BEARD, the former noun compound (LEMON MARKET) being more easily integrated than the latter (BEARD MARKET). Coolen et al. found a small $(16 \mathrm{~ms})$ but significant integration effect, with target words eliciting faster responses after a highly integrative prime than after a less integrative prime. In another experiment, Coolen and colleagues presented both lexicalized compounds (e.g., CHEESECAKE) and novel compounds (e.g., SLUMBUILDING), and the participants' task was to indicate whether the given compound was lexicalized (i.e., an existing compound) or novel. In fact, they presented two types of novel compounds - some were highly interpretable (e.g., SLUMBUILDING), while others were less interpretable (e.g., PARAKEETFIBER). They found that rejection of the highly interpretable novel compounds was slower and less accurate than rejection of the low interpretability compounds. Successful integration of a novel compound interfered with the "nonlexicalized" response. Coolen and colleagues thus demonstrated not only that relational integration affects lexical processing, but also that it may occur in tasks for which it actually hinders performance. These findings therefore suggest that relational integration is an uncontrolled component of lexical processing.

However, the study by Coolen et al. (1991) suffers from two important limitations. First, although Coolen et al. showed a relative difference in response times for highly integrative and less integrative word pairs, their demonstration did not distinguish between facilitation of the highly integrative pairs and interference of the less integrative pairs. Only if a target elicits faster responses after an integrative prime than after a neutral prime can facilitation be concluded. Second and perhaps more critically, their results are also equivocated by potential confounding 
factors. Although associative relatedness was matched across the highly integrative and less integrative pairs, similarity and familiarity were not. Thus, these results are more tentatively suggestive than definitively indicative of integrative priming.

Overview of Experiments

The present experiments were undertaken with two primary goals in view: Our empirical goal was to document integrative priming and to describe its properties, and our theoretical goal was to test whether any extant model can account for integrative priming. In each of the experiments we either controlled or manipulated the associative strength, semantic similarity, and compound familiarity of the prime and target concepts. To facilitate comparison with prior studies, we also manipulated two key factors that are often employed in investigations of lexical priming. First, in Experiments 1 and 2 we compared integrative priming to associative priming and semantic priming (respectively) across manipulations of stimulus onset asynchrony (SOA), which is the delay between onset of the prime and onset of the target. This factor is typically manipulated in order to investigate the time-course of a priming mechanism. For instance, both associative priming and semantic priming are observed at short (i.e., $<300 \mathrm{~ms}$ ) and intermediate SOAs (approximately 300 to $800 \mathrm{~ms}$ ), but associative priming continues to increase in magnitude across longer SOAs (i.e., $\geq 1000 \mathrm{~ms}$ ) whereas semantic priming tends to dissipate at those later SOAs (e.g., den Heyer, Briand, \& Smith, 1985; Hutchison, Balota, Cortese, \& Watson, 2008; Neely, 1977; Perea \& Rosa, 2002).

Second, in Experiments 3 and 4 we manipulated the relatedness proportion $(R P)$, which is the proportion of trials in which the prime and target words are related. This is a key factor for determining whether the priming mechanism is under strategic control by participants. If a mechanism is "controlled," then its effect should be accentuated when that mechanism is effective for task performance, and should be attenuated when the mechanism would be 
ineffective. To illustrate, suppose that primes and targets are easily integrated on $80 \%$ of the trials. In this case, relational integration would likely facilitate verification of the targets, and hence the integrative priming effect should be large. But if only $20 \%$ of trials were easily integrated, then relational integration would not be effective, and thus the effect should be diminished or altogether absent. So the occurrence of a RP effect is commonly held to indicate controlled processing, and conversely if an effect is impervious to RP manipulations then the mechanism is said to be "uncontrolled" (for review see Hutchison, 2007, Table 1). ${ }^{2}$

Because relational integration is so extensively practiced (Gagné, 2000), we hypothesized that it is an automated component of lexical processing. More specifically, we predicted that integrative priming would occur rapidly (i.e., at brief SOAs) and uncontrollably (i.e., regardless of RP). Together these experiments will delineate the basic properties of integrative priming.

\section{Experiment 1}

In Experiment 1 we sought the first unequivocal evidence of integrative priming. We therefore compared response times for the same target word following either an integrative prime or a neutral baseline prime. The integrative primes were constrained to be dissimilar to and unassociated with their targets, so that any observed difference between the baseline and integrative conditions would not be attributable to semantic or associative priming. For comparison to a well established lexical priming effect, we also included associative primes. Thus, the same target word (e.g., WINE) followed either a baseline prime (i.e., $* * * * * * * *)$, an associative prime (e.g., CORK), or an integrative prime (e.g., BOX). The targets were more strongly associated with their associative primes than with their integrative primes, and were more easily integrated into a sensible phrase with their integrative primes than with their associative primes. 
Associative priming generally increases from brief to long SOAs (see Hutchison, 2003, Table 3; see also Hutchison et al., 2008). To compare this pattern of associative priming to the presumed integrative priming, we used an intermediate SOA of $500 \mathrm{~ms}$ and a late SOA of 2000 ms. This intermediate SOA is comparable to the $540 \mathrm{~ms}$ SOA used by Coolen and colleagues (1991) in their study of relational integration, and this late SOA is known to produce associative priming (den Heyer et al., 1985; Neely, 1991; Perea \& Rosa, 2002). The experiment therefore had a 3 (Prime: baseline, associative, integrative; within-participants) $\times 2$ (SOA: 500, $2000 \mathrm{~ms}$; between-participants) mixed design using a standard LDT.

\section{Method}

Participants. All participants in each of the experiments reported herein were undergraduates at the University of Georgia (except where otherwise noted), all received partial course credit for participation, and all spoke English as their native language. None participated in more than one of the experiments or rating tasks reported below. In Experiment 1, 62 participants were randomly assigned to the $500 \mathrm{~ms}(\mathrm{n}=31)$ or the $2000 \mathrm{~ms}(\mathrm{n}=31)$ SOA condition, and an additional 72 participants provided similarity ratings and integration ratings.

Stimuli. Stimuli were selected on the basis of associative strength, semantic similarity, and integratability. In anticipation of the subsequent experiments, 50 targets (e.g., BOOK) were each paired with an integrative prime (e.g., TRAVEL), an associative prime (e.g., AUTHOR), and a semantic prime (e.g., ARTICLE). Association values were obtained from the University of South Florida free association norms (Nelson, McEvoy, \& Schreiber, 2004). For each of the 150 primetarget pairs, we obtained both the forward (e.g., prime $\rightarrow$ target) and backward (e.g., target $\rightarrow$ prime) association probabilities.

Additionally, 24 participants rated the semantic similarity of all 150 prime-target pairs on a scale from 1 (not at all similar) to 7 (very similar). Because integration is known to affect 
perceived similarity (Bassok \& Medin, 1997; Estes, 2003a; Jones \& Love, 2007; Simmons \& Estes, 2008; Wisniewski \& Bassok, 1999), it was important to emphasize to participants that they should rate featural similarity (McRae \& Boisvert, 1998). Thus, the instructions stated the following: "For example, DOTS and STRIPES are similar (both are types of patterns or designs). However, SHIRT and STRIPES would not be similar. Even though stripes are often found on shirts, a shirt is a type of CLOTHING. Furthermore, whereas ZEBRA is associated with STRIPES, these two words are also not very similar, because they belong to different categories (i.e., animal and pattern categories).”

Finally, we assessed integratability via a procedure adapted from Solomon and Pearlmutter (2004). An independent group of 27 participants rated the extent to which each of the 150 prime-target pairs, presented individually in isolation, could be linked together to produce a sensible phrase. The scale ranged from 1 (not linked) to 7 (tightly linked). We again distinguished between similarity and integration in the instructions: "For example, although KETCHUP and MUSTARD are similar in meaning and are often associated with each other, these words cannot be linked to form a sensible phrase. On the other hand, SILVER BRACELET could be linked together as a BRACELET made of SILVER."

Experimental stimuli were selected on the basis of the association values and the integration ratings. Forty-five targets, each paired with an associative prime and an integrative prime, were selected for use in the present experiment. All experimental stimuli are listed in Appendix A, and stimulus characteristics are summarized in Table 1. As evident in the table, the associated primes were more strongly associated with the targets, whereas the integrative primes were more easily integrated with the targets.

Because interpreting novel compounds in isolation may be somewhat unnatural, we also collected a contextualized measure of integratability by presenting the prime-target pairs in a 
neutral sentential context. All context sentences consisted of a common name as the subject, followed by a generic verb, and the target noun compound as a direct object (e.g., Betty asked about the TRAVEL BOOK). Twenty-one undergraduates at Francis Marion University judged "the sensibility of each word pair within its sentence" on a scale from 1 (not at all sensible) to 7 (completely sensible). For each target (BOOK), the same neutral sentence frame was used with each of the three prime types, though the sentences were presented in random order. Results were remarkably similar to the isolated integratability ratings reported in Table 1 . The integrative prime-target pairs $(M=5.32, S D=1.09)$ were judged more sensible than either the associative $(M=3.87, S D=1.03)$ or the semantic $(M=3.47, S D=.95)$ pairs. Moreover, the isolated and contextualized integratability ratings were correlated strongly $[r(135)=+.83, p<.001]$. Thus, the isolated and contextualized measures of integratability converged on the conclusion that the targets were more easily interpreted as a sensible phrase with their integrative primes than with their associative primes.

The associative primes were more similar to the targets than were the integrative primes (Table 1). This is most likely attributable to the negative relationship between semantic similarity and relational integration that is regularly observed in research on conceptual combination (Estes, 2003a; Wilkenfeld \& Ward, 2000; Wisniewski, 1996). The present stimulus set corroborates this general relationship: Across all stimulus pairs used in Experiments 1 and 2 (Appendix A), similarity ratings and integratability ratings exhibited a significant and relatively strong negative correlation, $r(135)=-.60, p<.001$. This covariation of similarity and integratability is addressed in the Results section. The only other significant intercorrelation among the variables presented in Table 1 was a positive relation between forward and backward association values, $r(135)=$ $+.30, p<.001$. 
In addition to the 45 experimental targets, there were also 45 pronounceable nonword targets (e.g., SKUP, REVICLE). Thirty nonword targets were preceded by a word prime (as in the associative and integrative conditions) and 15 were preceded by a row of eight asterisks (as in the baseline condition).

Procedure. Participants were tested individually in a sound-attenuated room, and the experiment was administered via DirectRT experimental software (version 2004) on Dell personal computers with 15 inch LCD displays and $17 \mathrm{~ms}$ refresh rate. Prime-type was manipulated within-participants, such that each participant was presented with 15 experimental targets in each of the three prime conditions (baseline, associative, integrative). Experimental items were rotated across three lists, with each target appearing only once per list. Participants initiated each trial by pressing the space bar. After a $500 \mathrm{~ms}$ pause, a red fixation $(+)$ appeared in the center of a black screen for $500 \mathrm{~ms}$. The prime then appeared centrally for $100 \mathrm{~ms}$, followed by a blank interval of either 400 or 1900 ms, depending on the SOA condition (i.e., 500, 2000 $\mathrm{ms})$. Finally, the target appeared centrally and remained on the screen until the participant indicated by key press whether the target was a word or a nonword. Primes were presented in red font in the center of a black screen, whereas targets appeared in white font. The relevant part of the instructions read as follows: "a red word (or a row of asterisks $* * * * * * * *$ ) will appear...but you don't have to respond to it. Then, a white letter string will appear, and your task is to indicate whether it's a word (e.g., 'giraffe') or not (e.g., 'blump')...The computer will be timing your responses, so please respond as quickly as you can, without making errors. And remember, you only have to respond to the second letter string (which will be in white), by pressing $\mathrm{J}$ for a word or F for a nonword". The inter-trial interval was one second. Ten practice trials preceded the 90 experimental trials.

Results and Discussion 
Both associative (e.g., CORK) and integrative (e.g., BOX) primes facilitated responding to target words (e.g., WINE), but they exhibited differential patterns of priming: Whereas associative priming increased across SOAs, integrative priming decreased across SOAs. The observed integrative priming was not attributable to association, similarity, or familiarity, and hence this experiment provided the first unequivocal evidence that relational integration facilitates lexical processing. Priming effects (i.e., Baseline RT - Experimental RT) are illustrated in Figure 1, and full results are presented in Table 2.

In each of the experiments reported herein, response times from incorrect trials and response times more than two standard deviations above or below the condition mean (calculated individually for each participant) were excluded from all analyses. Across experiments, this resulted in the removal of $2 \%$ to $5 \%$ of the data. In each experiment, results were analyzed separately across participants $\left(F_{\mathrm{p}}, t_{\mathrm{p}}\right)$ and items $\left(F_{\mathrm{i}}, t_{\mathrm{i}}\right)$. Data from the present experiment were analyzed initially via a 3 (Prime: baseline, associative, integrative) $\times 2$ (SOA: 500, $2000 \mathrm{~ms})$ mixed ANOVA. Accuracy rates exhibited only a main effect of Prime that was significant across participants $\left[F_{p}(2,120)=3.61, p<.05\right]$ but not across items $\left[F_{i}(2,88)=1.13, p=.33\right]$. Accuracy was not analyzed further.

The associative and integrative primes elicited faster responses than the baseline primes, as indicated by a significant main effect of Prime $\left[F_{p}(2,120)=19.19, p<.001\right.$ and $F_{i}(2,88)=$ $33.85, p<.001]$. Lexical decisions were also faster at the $500 \mathrm{~ms}$ SOA than at the $2000 \mathrm{~ms}$ SOA $\left[F_{p}(1,60)=5.29, p<.05\right.$ and $\left.F_{i}(1,44)=199.71, p<.001\right]$. Most importantly, associative priming and integrative priming exhibited different time-courses; the interaction of Prime and SOA was significant $\left[F_{p}(2,120)=3.04, p=.05\right.$ and $\left.F_{i}(2,88)=4.17, p<.05\right]$. To examine this interaction more closely, we conducted a further 2 (Prime: associative, integrative) $\times 2$ (SOA: 500, $2000 \mathrm{~ms}$ ) mixed ANOVA on the priming effects illustrated in Figure 1. Whereas associative 
priming increased across SOAs, integrative priming decreased across SOAs. This interaction was significant $\left[F_{p}(1,60)=6.95, p=.01\right.$ and $\left.F_{i}(1,44)=8.49, p<.01\right]$.

Recall that the target concepts were more similar to the associative primes than to the integrative primes (see Table 1). To investigate whether this conflation may explain the differential time-courses of the associative and integrative conditions observed here, we conducted a 2 (Prime: associative, integrative) $\times 2$ (SOA: 500, $2000 \mathrm{~ms}$ ) analysis of covariance across items, with similarity ratings included as the covariate. The effect of Similarity was nonsignificant $\left[F_{i}(1,87)=.64, p=.43\right]$, and the interaction of Prime and SOA again was significant $\left[F_{i}(1,87)=4.90, p<.05\right]$. Thus, similarity does not explain the divergent response patterns evident in Figure 1.

Finally, to examine whether the integrative priming observed here may be due to compound familiarity, we asked 29 undergraduates to rate the integrative prime-target pairs on a scale from 1 ("unfamiliar") to 7 ("very familiar"). Although the stimuli ranged in familiarity from 2.97 (MONKEY FOOT) to 6.76 (RACE CAR), these familiarity ratings did not correlate significantly with the magnitude of integrative priming (i.e., Baseline RT - Integrative RT) in either the $500 \mathrm{~ms}(r=-.23, p=.13)$ or the $2000 \mathrm{~ms} \mathrm{SOA}$ condition $(r=-.16, p=.28)$. Thus, the integrative priming was not attributable to compound familiarity.

In sum, relational integration facilitated lexical processing. The finding that target words elicited faster lexical decisions after an integrative prime than after a neutral baseline prime provides the first demonstration that the effect of relational integration is facilitative. Moreover, because the integrative primes and targets were unassociated and dissimilar (see Table 1), and because compound familiarity failed to explain the priming effect, the integrative priming observed here cannot be explained by any extant model of lexical priming. 
Whereas the preceding experiment dissociated integrative priming from associative priming, the present experiment compared integrative priming to semantic priming. The same target words (e.g., WINE) were preceded by either a baseline prime (i.e., ********), a semantic prime (e.g., GIN), or an integrative prime (e.g., BOX). Experiment 2 also examined in greater detail the temporal dynamics of integrative priming. Of particular interest were earlier and later SOAs, which would indicate whether integrative priming occurs rapidly and/or persists late. In addition to the intermediate SOA of $500 \mathrm{~ms}$, we also included a short SOA of $100 \mathrm{~ms}$ and two late SOAs of 1500 and $2500 \mathrm{~ms}$. Thus, the experiment had a 3 (Prime: baseline, semantic, integrative; within-participants $) \times 4(\mathrm{SOA}: 100,500,1500,2500 \mathrm{~ms}$; between-participants $)$ mixed design.

\section{Method}

Participants. One hundred seventy-five participants were randomly assigned to one of the four SOA conditions.

Stimuli. All experimental stimuli are reported in Appendix A, and stimulus characteristics are summarized in Table 1. Each of the 45 targets was paired with a semantic prime and an integrative prime. The targets were more similar to the semantic primes than to the integrative primes, but were more easily integrated with the integrative primes than with the semantic primes (Table 1). The semantic and integrative items were closely matched for both forward and backward association. The nonword targets were identical to those of Experiment 1.

Procedure. The procedure was identical to that of Experiment 1, except that the blank interval between prime offset and target onset was either $0,400,1400$, or $2400 \mathrm{~ms}$, depending on the SOA condition (i.e., 100, 500, 1500, $2500 \mathrm{~ms}$ ).

\section{Results and Discussion}


Full results are presented in Table 2, and priming effects are illustrated in Figure 2. As evident in the figure, the temporal dynamics of integrative priming were similar to those of semantic priming. Both were evident at the early SOA (100 ms), peaked at the intermediate SOA (500 ms), and then dissipated across the later SOAs (1500 and $2500 \mathrm{~ms})$. These results indicate that integrative priming, like semantic priming, emerges and dissipates rapidly.

Data were analyzed via a 3 (Prime: baseline, semantic, integrative; within-participants) $\times$ 4 (SOA: 100, 500, 1500, 2500 ms; between-participants) mixed ANOVA. Accuracy approached ceiling $(M=.99, S E=.002)$ and produced no significant effects (all $p s>.19)$. Relative to the baseline prime, semantic and integrative primes facilitated lexical decisions (see Figure 2), as indicated by a significant main effect of Prime on response times $\left[F_{p}(2,342)=18.46, p<.001\right.$ and $\left.F_{i}(1,88)=31.55, p<.001\right]$. The main effect of SOA was significant across items $\left[F_{i}(3,132)\right.$ $=32.78, p<.001]$ but not across participants $\left[F_{p}(3,171)=1.59, p=.19\right]$. The interaction failed to approach significance (both $p s>.28$ ). This lack of interaction suggests that each of the three prime-types produced similar response patterns across the various SOAs. This, in turn, indicates that integrative priming was not dissociated from semantic priming (see Figure 2). Indeed, paired comparisons of response times in the semantic and integrative conditions failed to approach significance within any of the four SOA conditions (all $p s \geq .20$ ).

As in the preceding experiment, we also examined whether the integrative priming could be due to compound familiarity. However, familiarity ratings (see Experiment 1) did not correlate significantly with integrative priming $(r=+.03, p=.83$, collapsed across SOAs). Evidently, the integrative priming was not attributable to compound familiarity. So once again, because the integrative primes were unassociated with and dissimilar to their targets, and because compound familiarity was unrelated to response times, the integrative priming observed here cannot be explained by extant models of lexical priming. 


\section{Experiment $3 \mathrm{~A}$}

Experiment 3A investigated whether integrative priming is controlled or uncontrolled. The hallmark of a controlled process is that its efficacy for task performance modulates the magnitude of its effect: Controlled processes are more likely to occur when they are adaptive for the given task than when they are ill-adaptive. For instance, when the majority of prime words can be easily integrated with their target words, then integration will be a successful strategy in the LDT. If the letter strings can be easily integrated, then the target must be a word. And if the letter strings cannot be easily integrated, then the target likely is a nonword. Thus, successful integration is highly predictive of the correct response. On the other hand, when relatively few of the prime words can be integrated with their target words, then integration will be a poor strategy for the task. If the letter strings are not easily integrated, the target could be either a word or a nonword. So in this case, integration is not predictive of the correct response.

Coolen et al. (1991) conducted a preliminary investigation of the effect of relatedness proportion (RP) on relational integration. In their first experiment, half (30 out of 60) of the critical trials could be easily integrated. In another experiment, they included as filler trials a large number of individual words and nonwords, but half (15 out of 30$)$ of the critical word pairs were again easily integrated. They found an integration effect in both experiments. From this they concluded that integration is beyond strategic control. Unfortunately, however, that result is equivocal. In both of their experiments, successful integration of the critical word pairs was 50\% predictive of a correct response (i.e., 30/60 and 15/30). The individual word and nonword fillers in their second experiment are irrelevant to the integration RP, because only word pairs can be integrated. Thus, their experiments do not constitute a clear manipulation of RP.

Experiment 3A therefore tested whether integrative priming is controlled or uncontrolled by manipulating RP. In addition to the experimental integrative stimuli, some participants also 
judged a number of filler word pairs that were easily integrated (.80 RP condition), whereas other participants judged filler pairs that were difficult to integrate (.20 RP condition), so that the proportion of integrative items varied across RP conditions. The experiment thus employed a 2 (Prime: baseline, integrative; within-participants) $\times 2$ (RP: .20, .80; between-participants) mixed design. If relational integration is controlled, then the integrative priming effect should be larger in the $.80 \mathrm{RP}$ condition than in the $.20 \mathrm{RP}$ condition. Alternatively, if relational integration is uncontrolled, then integrative priming should be invariant across RPs. Because RP effects tend to occur with SOAs greater than 300 ms (Henik, Friedrich, Tzelgov \& Tramer, 1994; Hutchison, Neely, \& Johnson, 2001; Perea \& Rosa, 2002; Stolz, Besner, \& Carr, 2005; Stolz \& Neely, 1995), we used a $500 \mathrm{~ms}$ SOA.

\section{Method}

Participants. One hundred twenty-five undergraduates were randomly assigned to the .20 $(n=63)$ or the $.80(n=62)$ RP condition.

Stimuli. The experimental stimuli were a subset of 30 items from those used in Experiments 1 and 2 (denoted with an asterisk in Appendix A). The integratability $(M=5.42, S D$ $=0.82)$, forward association $(M=0.01, S D=0.01)$, backward association $(M=0.00, S D=0.01)$, and similarity $(M=2.04, S D=0.66)$ of this subset of stimuli were comparable to those of the entire stimulus set used in the preceding experiments (see Table 1, "Integrative"). Items were rotated across experimental lists, such that 15 of the critical targets were preceded by their integrative prime (i.e., integrative condition), 15 targets were preceded by a row of eight asterisks (i.e., baseline condition), and no target appeared more than once.

In order to manipulate RP, we included filler stimuli that were either easy or difficult to integrate. RP is defined as the proportion of word $\rightarrow$ word trials in which the prime and target words are related (Neely et al., 1989; Tweedy et al., 1977). We counted integrative prime-target 
trials as "related," and non-integrative prime-target trials as "unrelated." In the .80 RP condition there were 45 integrative fillers (e.g., TOMATO $\rightarrow$ sOUP) and 15 non-integrative fillers (e.g., TURNIP $\rightarrow$ FONT). Thus, each experimental list in the .80 RP condition included 15 critical integrative trials, 45 filler integrative trials, and 15 filler non-integrative trials $(\mathrm{RP}=60 / 75=.80)$. In the $.20 \mathrm{RP}$ condition there were 60 non-integrative filler pairs. Thus, each experimental list in the $.20 \mathrm{RP}$ condition included 15 critical integrative trials and 60 filler non-integrative trials (RP $=15 / 75=.20$ ). To confirm that the "integrative" fillers were highly integrative and that the "nonintegrative" fillers indeed were difficult to integrate, all filler pairs were rated for integratability $(\mathrm{N}=35)$ following the "isolated" procedure of Experiment 1. The mean of the integrative fillers was $5.99(S D=0.76)$, thus confirming that they were highly integrative. The mean of the nonintegrative fillers was $2.08(S D=0.60)$, supporting the assumption that those items indeed were difficult to integrate. In both conditions there were also 60 baseline fillers (e.g., ******** $\rightarrow$ GOOSE) and 150 nonword targets, half of which were preceded by a prime word (e.g., FARM $\rightarrow$ RAMUS) and half of which were preceded by the baseline prime (e.g., ******** $\rightarrow$ REVICLE). Thus, the experiment consisted of 300 trials presented in random order.

Procedure. The procedure was identical to the $500 \mathrm{~ms}$ SOA condition of the preceding experiments. Ten practice trials preceded the 300 experimental trials. There was a self-paced break midway through the experiment.

\section{Results and Discussion}

Full results are presented in Table 3, and priming effects are illustrated in Figure 3A. As evident in the figure, relational integration facilitated lexical processing, and this integrative priming effect was invariant across the .20 and the $.80 \mathrm{RP}$ conditions. This apparent lack of strategic mediation suggests that relational integration is uncontrolled. 
Data were analyzed via 2 (Prime: baseline, integrative; within-participants) $\times 2$ (RP: .20, .80 ; between-participants) mixed ANOVA. Accuracy was near ceiling $(M=.99, S E=.003)$ and exhibited no significant effects (all $p s>.25$ ). The targets elicited faster lexical decisions after an integrative prime $(M=550, S E=8)$ than after a baseline prime $(M=580, S E=7),\left[F_{p}(1,123)=\right.$ $30.71, p<.001$ and $\left.F_{i}(1,29)=48.16, p<.001\right]$. Consistent with the preceding experiments, the present result demonstrates that the effect of relational integration indeed is facilitative. There was no indication that RP modulates integrative priming, as neither the main effect of $\mathrm{RP}\left[F_{p}(1\right.$, $123)=.27, p=.60$ and $\left.F_{i}(1,29)=3.73, p=.06\right]$ nor its interaction with Prime was significant $\left[F_{p}(1,123)=.31, p=.58\right.$ and $\left.F_{i}(1,29)=.25, p=.62\right]$. Moreover, paired comparisons confirmed that the integrative priming effect was significant in both the $.20 \mathrm{RP}$ condition $\left[t_{p}(62)=3.23, p<\right.$ .01 and $\left.t_{i}(29)=3.64, p<.01\right]$ and the $.80 \mathrm{RP}$ condition $\left[t_{p}(61)=4.82, p<.001\right.$ and $t_{i}(29)=3.97$, $p<.001]$. Once again, compound familiarity was unrelated to the magnitude of integrative $\operatorname{priming}(r=-.27, p=.15$, collapsed across RPs).

These results suggest that relational integration is uncontrolled. If relational integration were controlled or adaptable, then this strategy should be employed more often when the majority of word pairs are easily integrated than when they are not. Thus, the integrative priming effect should have been larger in the $.80 \mathrm{RP}$ condition than in the $.20 \mathrm{RP}$ condition. Indeed, the integration strategy would be ill-adaptive when only $20 \%$ of the word targets (and only $10 \%$ of all trials) could be integrated. Yet, integrative priming was just as prevalent and just as sizeable in the .20 condition as in the .80 condition, presumably because relational integration is beyond strategic control.

\section{Experiment 3B}

Although we have attributed the absence of a RP effect in Experiment 3A to a lack of strategic control of relational integration, it could be due alternatively to some unknown 
methodological factor. To test this explanation, Experiment 3B was an exact replication of Experiment 3A, except that the integrative primes were replaced by semantic primes. Because semantic priming is under strategic control, it is sensitive to manipulations of RP (Hutchison, 2007; Neely et al., 1989). We therefore expected a significant RP effect in the present experiment. If obtained, this would demonstrate that the null RP effect of the preceding experiment was not due to methodological factors.

\section{Method}

Participants. One hundred forty undergraduates were randomly assigned to the $.20(\mathrm{n}=$ 70) or the $.80(\mathrm{n}=70) \mathrm{RP}$ condition.

Stimuli. Stimuli consisted of experimental prime-target pairs that were similar, filler pairs that were either highly similar or dissimilar (in the different RP conditions), and filler pairs that had a nonword target. The 30 experimental targets used in Experiment $3 \mathrm{~A}$ were paired with semantic primes here in Experiment 3B (see Appendix A). The integratability $(M=3.06, S D=$ $0.80)$, forward association $(M=0.03, S D=0.03)$, backward association $(M=0.01, S D=0.03)$, and similarity $(M=4.54, S D=0.86)$ of this subset of stimuli were comparable to those of the entire stimulus set used in Experiment 2 (see Table 1, "Semantic"). The proportions of items in the .20 and .80 conditions paralleled those of Experiment 3A, with 45 highly similar filler items (e.g., ROBIN $\rightarrow$ CANARY) taken from Lupker (1984), McRae and Boisvert (1998), and Moss et al. (1995). The pairs with a nonword target were the same as in Experiment 3A.

Procedure. The procedure was identical to Experiment 3A.

\section{Results and Discussion}

Unlike integrative priming (Figure 3A), semantic priming was modulated by the proportion of related primes and targets (Figure 3B). This RP modulation corroborates prior demonstrations that semantic priming is under strategic control (Hutchison, 2007; Neely et al., 
1989), and suggests that the lack of RP modulation in Experiment 3A was not due to spurious methodological factors. Full results are presented in Table 3, and priming effects are illustrated in Figure 3B.

Data were analyzed via 2 (Prime: baseline, semantic; within-participants) $\times 2$ (RP: .20, .80; between-participants) mixed ANOVA. Analysis of accuracy rates revealed only a main effect of RP $\left[F_{p}(2,120)=3.61, p<.05\right.$ and $\left.F_{i}(1,29)=4.57, p<.05\right]$, with higher accuracies in the $.20 \mathrm{RP}$ condition $(M=.995, \mathrm{SE}=.002)$ than in the $.80 \mathrm{RP}$ condition $(M=.988, S E=.002)$. The targets elicited faster lexical decisions after a semantic prime $(M=568, S E=9)$ than after a baseline prime $\left[M=588, S E=8 ; F_{p}(1,138)=11.10, p=.001\right.$ and $\left.F_{i}(1,29)=14.98, p=.001\right]$. The main effect of RP was reliable by items $\left[F_{i}(1,29)=21.68, \mathrm{p}<.001\right]$ but not by participants $\left[F_{p}(1,138)=1.70, p=.19\right]$. Most importantly, however, RP modulated semantic priming (see Figure 3B): The RP $\times$ Prime interaction was significant $\left[F_{p}(1,138)=4.05, p<.05\right.$ and $F_{i}(1,29)$ $=6.73, p<.05]$, and paired comparisons confirmed that the semantic priming effect was significant in the $.80 \mathrm{RP}$ condition $\left[t_{p}(69)=4.10, p<.001\right.$ and $\left.t_{i}(29)=4.46, p<.001\right]$ but not in the $.20 \mathrm{RP}$ condition $\left[t_{p}(69)=.87, p=.39\right.$ and $\left.t_{i}(29)=1.05, p=.30\right]$. This finding replicates previous findings of a RP effect on semantic priming (e.g., Hutchison, 2007; Neely et al., 1989).

Given that the relation between prime and target words was the only systematic difference between Experiments 3A (integrative) and 3B (semantic), the lack of RP effect with integrative primes in Experiment $3 \mathrm{~A}$ evidently was not attributable to procedural factors. Collectively, Experiments 3A and 3B thus provide suggestive evidence of a dissociation of integrative priming and semantic priming. Whereas semantic priming is subject to strategic control, integrative priming appears to be uncontrolled. 
Experiment 4 replicated Experiment 3A, but with a different baseline condition and different measures of compound familiarity. In studies of lexical priming, there is no universally accepted baseline condition. The use of neutral symbols (e.g., ******** or XXXXXXXX) is common, but may be criticized for not engaging the lexical system, not controlling lexical processing, and/or not maintaining attention on the task. Consequently, any observed difference between such a neutral baseline condition and an experimental word prime condition may be attributed to any of these factors. Or to state it more concretely, the faster responding after an integrative prime than after a neutral prime could reflect a response delay from the neutral primes rather than a response facilitation from the integrative primes. These criticisms suggest the use of unrelated words as primes, and indeed this is another common baseline condition (see Hutchison, 2003, Table 2). However, this approach may be criticized too, as an unrelated prime may actually interfere with the process of interest. For example, faster responding after an integrative prime than after an unrelated word prime could be due either to facilitation via integration or to interference from the unrelated word. The most conservative approach, then, is to use both types of baseline. Given that the preceding experiments have demonstrated integrative priming relative to a neutral baseline (i.e., $* * * * * * * * \rightarrow$ WINE), in Experiment 4 we tested for integrative priming relative to an unrelated word baseline (e.g., COPPER $\rightarrow$ WINE).

Experiment 4 also included different measures of the compound familiarity of the primetarget pairs. In Experiments 1, 2, and 3A we reported that participants' familiarity ratings did not correlate with the magnitude of integrative priming. However, McKoon and Ratcliff (1992) noted that subjective ratings may not provide the best measure of familiarity. They argued that the frequency of co-occurrence in large samples of written language provides the best estimate of prime-target familiarity. Thus, in order to reject more conclusively a compound familiarity explanation of integrative priming, in Experiment 4 we measured compound familiarity in terms 
of both local and global co-occurrence. Local co-occurrence is the frequency with which two words occur directly adjacent to one another in a large text corpus, whereas global co-occurrence is the frequency with which two words occur in the same or similar documents within a large text corpus. In Experiment 4 we measured local co-occurrence via Google hits (i.e., the number of occurrences of the given noun compound in the Google internet search engine), which have been shown to predict comprehension times of noun compounds (Wisniewski \& Murphy, 2005). We measured global co-occurrence via latent semantic analysis (LSA; Landauer \& Dumais, 1997).

We also examined whether local and global co-occurrence were related to integrative priming in the preceding experiments. For this analysis we used the 30 integrative prime-target pairs that were common to Experiments 1,2, and 3A, and we collapsed across SOAs in Experiment 2 and across RPs in Experiment $3 \mathrm{~A}$ because those factors did not interact with prime-type. Google hits and LSA values were both positively skewed, so both were log transformed for normalization. Importantly, both Google hits and LSA values diverged from familiarity ratings: Familiarity ratings were only moderately related to Google hits $(r=+.40, p<$ $.05)$, and were unrelated to LSA values $(r=+.07, p=.73)$. Moreover, Google hits and LSA values were also unrelated to one another $(r=+.19, p=.31)$. Given the divergence of these three measures of familiarity, it is feasible that local co-occurrence (Google hits) and/or global cooccurrence (LSA values) could explain the observed integrative priming even though subjective familiarity (participant ratings) did not. In fact, though, none of the three measures was significantly correlated with the magnitude of integrative priming in either Experiment 1 (either SOA condition), Experiment 2, or Experiment 3A (all $p s \geq .10$ ). Nevertheless, given the suggestion that compound familiarity is best measured by co-occurrence (McKoon \& Ratcliff, 1992), we included both Google hits and LSA values as controls for compound familiarity here in Experiment 4. 
Finally, Experiment 4 also replicated the RP manipulation of Experiment 3A, but for purposes of generality we used a different stimulus set. Thus, the experiment had a 2 (Prime: baseline, integrative; within-participants $) \times 2$ (RP: .20, .80; between-participants) mixed design . A larger priming effect in the $.80 \mathrm{RP}$ condition than in the $.20 \mathrm{RP}$ condition would indicate that relational integration is controlled, whereas a priming effect that is invariant across RPs would suggest that relational integration is uncontrolled.

\section{Method}

Participants. One-hundred four undergraduates were randomly assigned to the $.20(\mathrm{n}=$ $53)$ or the $.80(n=51)$ RP condition. An additional 25 undergraduates participated in an integratability rating task.

Stimuli. Integrative stimuli (see Appendix B) consisted of 10 prime-target pairs from Experiment 3A (e.g., WINTER $\rightarrow$ SPORT) and 20 new pairs (e.g., STABLE $\rightarrow$ COW). The unrelated baseline pairs were created by re-pairing the 30 integrative primes with other targets (e.g., WINTER $\rightarrow$ COW), such that the global co-occurrence (i.e., LSA cosine) of each integrative pair was matched as closely as possible to its corresponding unrelated pair. Thus, the integrative $(M=$ $0.08, S D=0.04)$ and unrelated pairs $(M=0.08, S D=0.05)$ did not differ in global co-occurrence. They did differ in local co-occurrence, however: Log Google hits (as sampled on 24 August 2008) were greater for integrative pairs $(M=5.15, S D=1.22)$ than for unrelated pairs $(M=3.95$, $S D=1.21)$. This conflation of local co-occurrence and prime-type is addressed in the Results section below. The unrelated pairs were strictly unassociated $(M=0.00)$, and the integrative pairs were virtually unassociated (forward $M=0.01, S D=0.01$; backward $M=0.00, S D=0.01$ ).

Twenty-five participants rated the integratability of the stimuli on a scale from 1 to 7 (see "isolated" rating task of Experiment 1 for detail). The 60 prime-target pairs were balanced and rotated across two lists, so that each participant rated 15 integrative pairs and 15 unrelated pairs, 
and each participant rated each target only once. Ratings confirmed that the integrative pairs $(M$ $=5.06, S D=1.22)$ were easier to integrate than the unrelated pairs $(M=2.18, S D=0.94)$.

Although the ranges for the integrative $(2.28-6.64)$ and unrelated pairs $(1.16-4.84)$

overlapped, 29 of the 30 targets were more easily integrated with their integrative prime than with their unrelated prime. One target was integrated marginally more easily with its unrelated prime $($ CHAIN ISLAND $=2.96)$ than with its integrative prime $($ MONKEY ISLAND $=2.28)$.

Filler stimuli were taken from Experiment 3A. The .20 RP condition included 45 nonintegrative fillers (integratability $M=2.10, S D=0.62$ ), whereas the $.80 \mathrm{RP}$ condition included 45 integrative fillers $(M=5.96, S D=0.76)$.

Procedure. The procedure was the same as Experiment $3 \mathrm{~A}$.

\section{Results and Discussion}

Full results are presented in Table 3, and priming effects are illustrated in Figure 3C. Results replicated Experiment 3A: Relational integration facilitated lexical decisions, and this integrative priming effect was invariant across the .20 and the $.80 \mathrm{RP}$ conditions (see Figure $3 \mathrm{C}$ ).

Data were analyzed by a 2 (Prime: baseline, integrative; within-participants) $\times 2$ (RP: .20, .80; between-participants) mixed ANOVA. Accuracy rates exhibited only a main effect of RP that was significant across items $\left[F_{i}(1,29)=47.21, p<.001\right]$, such that accuracy was higher in the $.80 \mathrm{RP}$ condition $(\mathrm{M}=.99, \mathrm{SE}<.01)$ than in the $.20 \mathrm{RP}$ condition $(\mathrm{M}=.97, \mathrm{SE}=.01)$. However, this effect was not significant across participants $\left[F_{p}(1,102)=.73, p=.40\right]$. Responses were a reliable $15 \mathrm{~ms}$ faster after the integrative primes $(M=546, S E=7)$ than after the unrelated baseline primes $\left[M=561, S E=8 ; F_{p}(1,102)=8.40, p<.01\right.$ and $\left.F_{i}(1,29)=20.83, p<.001\right]$. Neither the main effect of $\operatorname{RP}\left[F_{p}(1,102)=.05, p=.82\right.$ and $\left.F_{i}(1,29)=1.06, p=.31\right]$ nor its interaction with Prime $\left[F_{p}(1,102)=.04, p=.84\right.$ and $\left.F_{i}(1,29)=.13, p=.72\right]$ approached significance. Paired comparisons revealed significant integrative priming in both the $.20 \mathrm{RP}$ 
condition $\left[t_{p}(52)=2.00, p=.05\right.$ and $\left.t_{i}(29)=2.80, p<.01\right]$ and the $.80 \mathrm{RP}$ condition $\left[t_{p}(50)=\right.$ $2.09, p<.05$ and $\left.t_{i}(29)=3.30, p<.01\right]$. Thus, as in Experiment 3A, RP did not modulate integrative priming.

Although the integrative and the unrelated word pairs were matched closely for association and global co-occurrence (LSA values), recall that local co-occurrence (Google hits) was greater among integrative pairs than among unrelated pairs. We therefore tested for a relation between local co-occurrence and integrative priming in two ways. First we tested whether the difference in local co-occurrence (i.e., Google integrative - Google $_{\text {unrelated }}$ ) predicted the magnitude of integrative priming (i.e., $\left.\mathrm{RT}_{\text {unrelated }}-\mathrm{RT}_{\text {integrative }}\right)$. It $\operatorname{did} \operatorname{not}(r=-.07, p=.73)$.

Second, we also tested whether local co-occurrence of the integrative pairs (i.e., Google integrative $_{\text {) }}$ moderated the magnitude of integrative priming (i.e., $\left.\mathrm{RT}_{\text {unrelated }}-\mathrm{RT}_{\text {integrative }}\right)$. It $\operatorname{did}(r=-.37, p<$ $.05)$, but this relationship was the opposite of what the compound cue model would predict. That is, more familiar integrative compounds such as POOL PARTY $(\log$ Google $=6.82)$ exhibited less integrative priming than unfamiliar integrative compounds such as LECTURE SLEEP $(\log$ Google $=$ 2.87). To examine this relationship more closely, we performed a median split on the local cooccurrence of the integrative pairs, and then we tested whether highly familiar and less familiar compounds exhibited integrative priming separately. Although the integrative priming effect was twice as large among less familiar compounds $(M=20, S E=6)$ as among more familiar compounds $(M=10, S E=3)$, both groups of compounds nonetheless exhibited significant integrative priming [unfamiliar $t(14)=3.61, p<.01$; familiar $t(14)=3.18, p<.01$ ]. In sum, local co-occurrence did moderate the magnitude of integrative priming, but there appears to be more to integrative priming than just local co-occurrence.

Given that only the stimuli differed between Experiments $3 \mathrm{~A}$ and 4, we conducted further analyses across participants from both of these experiments combined $(\mathrm{N}=229)$. A 2 (Prime: 
baseline, integrative; within-participants $) \times 2(\mathrm{RP}: .20, .80$; between-participants $) \times 2$

(Experiment: 3A, 4; between-participants) mixed ANOVA revealed no effects in the accuracy data. However, lexical decisions to targets were significantly faster following an integrative prime $(M=548, S E=5)$ than following a baseline prime $\left[M=571, S E=5 ; F_{p}(1,225)=35.02, p\right.$ $<.001]$. The interaction of Prime and Experiment was marginally significant $\left[F_{p}(1,225)=3.45\right.$, $p=.065]$. Table 3 reveals that this near-interaction was attributable to the baseline conditions: Targets elicited slower responses after the neutral baseline prime (Experiment $3 \mathrm{~A}$ ) than after an unrelated word prime (Experiment 4). Target responses following an integrative prime, in contrast, were equally fast across experiments. Most critically, the effect of RP once again failed to approach significance $\left[F_{p}(1,225)=.04, p=.84\right]$. Across experiments, integrative priming was significant in both the $.20 \mathrm{RP}$ condition $\left[M=21, S E=6, t_{p}(115)=3.78, p<.001\right]$ and the $.80 \mathrm{RP}$ condition $\left[M=25, S E=5, t_{p}(112)=4.89, p<.001\right]$. No other main effect or interaction was significant (all ps $>.24)$.

Three aspects of this result are notable. First, given that integrative primes have elicited faster responses than both neutral symbol primes (Experiment 3A) and unrelated word primes (Experiment 4), it appears unequivocal that relational integration facilitates lexical decisions. Second, given that neither local co-occurrence nor global co-occurrence explained integrative priming (see McKoon \& Ratcliff, 1992), the integrative priming effect cannot be attributed to compound familiarity. Finally, the equivalent magnitude of integrative priming across the high and low RP conditions corroborates the conclusion that relational integration is uncontrolled. ${ }^{3}$ So whereas semantic priming is modulated by RP (Experiment 3B; see also Hutchison, 2007), integrative priming is unaffected by RP (Experiments $3 \mathrm{~A}$ and 4 ). This result constitutes a dissociation of semantic priming and integrative priming, albeit between experiments. 
These experiments provide the first unequivocal demonstration that relational integration facilitates lexical processing. Across experiments, lexical decisions for the exact same target words were faster when preceded by a prime word with which they could be easily integrated into a sensible phrase (e.g., BOX $\rightarrow$ WINE) than when preceded by a neutral baseline prime (e.g., $* * * * * * \rightarrow$ WINE) or an unrelated word prime (e.g., COPPER $\rightarrow$ WINE). Experiments 1 and 2 used a variable prime-target SOA to compare the temporal dynamics of this integrative priming (e.g., BOX $\rightarrow$ WINE) with those of associative priming (e.g., CORK $\rightarrow$ WINE) and semantic priming (e.g., GIN $\rightarrow$ WINE). Integrative priming was dissociated from associative priming at a $2000 \mathrm{~ms}$ SOA (Experiment 1), but closely resembled semantic priming from early (100 ms) to late $(2500 \mathrm{~ms})$ SOAs (Experiment 2). Like semantic priming, integrative priming emerged rapidly and asymptoted early. Experiments $3 \mathrm{~A}$ and 4 demonstrated that, unlike semantic priming (Experiment 3B), integrative priming is uncontrollable: Integrative priming was consistent across low (.20) and high (.80) RP conditions. In sum, then, relational integration produced rapid and uncontrollable integrative priming among concepts that are dissimilar and unassociated and that are unfamiliar as a phrase.

\section{Extant Models of Lexical Priming}

These results are not explicable via any extant model of lexical priming. Because the integrative prime-target pairs were unassociated, dissimilar, and unfamiliar, the observed integrative priming cannot be attributed to associative strength, featural similarity, or compound familiarity. Consider the concepts MONKEY and FOOT. When given MONKEY as a cue word in the free association task, participants rarely if ever produce FOOT in response. The two concepts do not share many features, they do not form a familiar compound, and they do not co-occur frequently in ordinary language. Yet MONKEY facilitates lexical processing of FOOT. Clearly, any model that ascribes lexical priming to association, similarity, or familiarity (e.g., spreading 
activation, distributed representation, expectancy, semantic matching, episodic retrieval, compound cue) fails to explain the priming that occurs with these and other integrative concepts. To be clear, we are not suggesting that the extant models be rejected as generally incorrect or inapplicable to priming phenomena. On the contrary, these models were entertained precisely because their viability is widely supported by prior studies. Our claim is simply that integrative priming, in particular, is not explained by any of these models. Under the present conditions, some other mechanism must explain the priming. The most likely and natural explanation is that the prime and target concepts are easily integrated into a sensible compound representation, and that this relational integration occurs rapidly and uncontrollably during lexical processing (see also Coolen et al., 1991; Seidenberg et al., 1984). Below we consider some basic cognitive mechanisms that, in light of the present results, could explain how integrative priming occurs. First, however, we consider the reliability of integrative priming across individuals.

\section{Individual Differences in Integrative Priming}

Stolz et al. (2005) conducted an in-depth investigation of the reliability of semantic priming across participants and across items (see also Hutchison et al., 2008). They orthogonally crossed SOA $(200,350,800 \mathrm{~ms})$ and RP $(.25, .50, .75)$, testing a total of 720 individuals. Stolz and colleagues found that, overall, about $15 \%$ of participants exhibited no semantic priming. Although the present experiments were not designed for this purpose, we nonetheless examined priming effects at the level of individual participants. For each participant, we compared the mean RT in the experimental conditions (e.g., integrative, associative, semantic) to the mean RT in the baseline condition to determine whether the experimental primes facilitated target word recognition (i.e., priming). Table 4 shows descriptive statistics in terms of both prevalence (i.e., percentage of participants exhibiting a priming effect) and magnitude (i.e., effect size among those participants) in each of the experiments separately. 
In Experiment 1, 81\% of participants exhibited associative priming, $74 \%$ exhibited integrative priming, and $65 \%$ exhibited both integrative and associative priming. This finding suggests that most participants engaged in multiple retrieval processes simultaneously; the processes that yield integrative priming and associative priming are not mutually exclusive. The prevalence of associative priming was constant at $81 \%$ across both the 500 and 2000 SOA conditions. Thus, the increase in associative priming across SOAs (see Fig. 1) was due to an increase in magnitude rather than prevalence. That is, of the participants who exhibited associative priming, the mean effect size increased from $58 \mathrm{~ms}$ in the 500 SOA condition to 91 $\mathrm{ms}$ in the $2000 \mathrm{SOA}$ condition. In contrast, the diminution of the integrative priming effect across SOAs (Fig. 1) was due to a decrease in prevalence rather than magnitude. Within the 500 and 2000 SOA conditions, $81 \%$ and $68 \%$ of participants respectively exhibited integrative priming. Of the participants who exhibited integrative priming, the mean effect sizes were $57 \mathrm{~ms}$ and 56 $\mathrm{ms}$ in the 500 and 2000 SOA conditions respectively. Because fewer participants exhibited this priming effect in the 2000 SOA condition than in the 500 SOA condition, the overall magnitude of the priming effect diminished across SOAs.

In Experiment 2, 66\% and 63\% of participants exhibited semantic priming and integrative priming respectively, with $52 \%$ exhibiting both types of priming. Across the increasing SOAs, both types of priming exhibited an initial increase and a subsequent decrease in both prevalence and magnitude. This pattern corroborates that observed in overall response times (Fig. 2).

In Experiment 3A, $72 \%$ of participants exhibited integrative priming, with a mean magnitude of $54 \mathrm{~ms}$. The prevalence and magnitude of integrative priming were virtually identical across the .20 and $.80 \mathrm{RP}$ conditions. In Experiment 3B, $65 \%$ of participants exhibited semantic priming, with a mean magnitude of $56 \mathrm{~ms}$. Unlike integrative priming, however, semantic priming was weaker in the $.20 \mathrm{RP}$ condition $(56 \%, 51 \mathrm{~ms})$ than in the $.80 \mathrm{RP}$ condition 
(74\%, $60 \mathrm{~ms}$ ). This result corroborates the effect of RP on semantic priming observed in the overall means (Fig. 3B). In Experiment 4, 63\% of participants exhibited integrative priming, with a mean magnitude of $46 \mathrm{~ms}$. The prevalence and magnitude of integrative priming again were virtually identical across the $.20 \mathrm{RP}$ condition and the $.80 \mathrm{RP}$ condition. Thus, in both Experiments $3 \mathrm{~A}$ and 4 , individual patterns of integrative priming were relatively constant across the RP manipulation. Experiment 3B, in contrast, revealed individual patterns of semantic priming that varied across RPs. This result suggests that integrative priming is uncontrolled, whereas semantic priming is controlled.

Across all experiments, we tested 606 participants for integrative, associative, and/or semantic priming. To compare the overall prevalence and magnitude of these different types of priming, we collapsed across all experiments. Of the 466 participants tested for integrative priming, 311 exhibited positive priming (67\%), with a mean magnitude of $59 \mathrm{~ms}$. Of the 315 who were tested for semantic priming, 207 exhibited positive priming (66\%), with a mean magnitude of $60 \mathrm{~ms}$. And of the 62 who were tested for associative priming, 50 exhibited positive priming (81\%), with a mean magnitude of $74 \mathrm{~ms}$. Integrative priming thus appears to be about as robust as semantic priming, and only slightly less robust than associative priming. Considering that integrative priming has been largely overlooked by cognitive psychologists, this is quite a striking observation.

An important goal for further study is to determine what participant factors contribute to integrative priming. The magnitude of semantic priming is predicted by an individual's perceptual ability (Plaut \& Booth, 2000), attentional control (Hutchison, 2007), working memory capacity (Kiefer, Ahlegian, \& Spitzer, 2005; Woltz \& Was, 2007), and reading skill (Nation \& Snowling, 1999). It seems likely that these same factors may also predict the magnitude of integrative priming. Consider for example working memory. In text comprehension, integrating a 
word into a larger context relies specifically on the verbal or semantic component of working memory rather than the phonological or spatial component (Fedorenko, Gibson, \& Rohde, 2007; Haarmann, Davelaar, \& Usher, 2003; Nation, Adams, Bowyer-Crane, \& Snowling, 1999). Verbal-semantic working memory thus may predict integrative priming as well. Once the participant factors contributing to integrative priming are identified, it will be important to test whether those factors are malleable. If they are, then training programs to improve those critical skills potentially could improve an individual's language comprehension abilities more generally.

\section{Possible Models of Integrative Priming}

In the introduction we alluded to basic cognitive mechanisms that might explain integrative priming. One possibility is to attribute integrative priming to a retrospective "integration check", whereby participants check whether the target can be integrated with the prime. If prime and target can be integrated, then the target must be a word; but if prime and target cannot be integrated, then the target could be either a word or a nonword. Hence, target words would elicit faster "word" responses when they are easily integrated with their prime than when not. Such an integration check is closely reminiscent of semantic matching, whereby participants check whether the target is associatively or semantically related to the prime. Indeed, it is tempting to simply include integratability as a third factor affecting the semantic matching process, so as to account for the priming observed among unassociated and dissimilar concepts in the present study. But the results of Experiments 3A and 4 indicate that integration checking and semantic matching are qualitatively different phenomena: Whereas semantic matching is controlled (Hutchison, 2007), integration checking is uncontrolled. A more general and serious limitation of the integration checking hypothesis is that it is more descriptive than explanatory. How exactly does one determine whether a target can be integrated with its prime, and how does this facilitate lexical processing? A more specific cognitive mechanism is required. 
In introducing integrative priming we have focused on relational integration. Implicit and essential to this relational integration, though, is a process of role assignment. That is, relational integration entails not only inferring a likely relation between concepts, but also assigning those concepts to complementary semantic roles (Cohen \& Murphy, 1984; Estes, 2003a; Jones \& Love, 2007; Wisniewski, 1997; Wisniewski \& Bassok, 1999; Wisniewski \& Love, 1998). ${ }^{4}$ In TABLE VASE, for example, the table is a location and the vase is the object. To see why this role resolution is critical, consider the compounds WIND EROSION and GROWTH HORMONE. Although both invoke a causal relation, notice that the cause occurs as modifier in the former and as head in the latter. Thus, simply inferring a sensible relation is insufficient for comprehension; one must also resolve which concepts perform which roles (Estes \& Jones, 2008). Consequently, the same pair of concepts can be integrated more easily in one direction (e.g., HORSE DOCTOR) than the other (e.g., DOCTOR HORSE; Jones, Estes \& Marsh, 2008), and integrative priming may differ accordingly.

Relational integration thus may be conceived as the resolution of a relational argument via binding of filler concepts to their respective relational roles. The following speculations about possible mechanisms of integrative priming are based on Hummel and Holyoak's (1997, 2003) model of relational concepts, which was substantially revised and extended by Doumas, Hummel, and Sandhofer (2008). A critical component of the model is that it contains semantic units not only for object concepts, but also for the relational roles that those objects fill. To illustrate how this model might be extended to integrative priming, consider the noun compound FOREST BIRD, which is understood by inferring a location relation that entails the roles of locale and object. Abstractly speaking, integrative priming would occur when the prime and target words (e.g., FOREST and BIRD) are easily assigned to complementary roles in a semantic relation 
(i.e., locale and object, respectively). Basic mechanisms that might facilitate role assignment are described next.

Noun concepts appear to be associated with the integrative relations that they most frequently instantiate. For example, FOREST frequently instantiates the location relation (e.g., FOREST BIRD, FOREST STREAM). As a result of this association, noun compounds are understood faster if they instantiate a relation that is frequent for the given modifier (e.g., FOREST BIRD) than if they instantiate a relation that is infrequent for that concept (e.g., FOREST STORY; Gagné \& Shoben, 1997; Storms \& Wisniewski, 2005; but see Maguire, Devereux, Costello \& Cater, 2007; Wisniewski \& Murphy, 2005). Note that this relation frequency effect can be interpreted alternatively as a role typicality effect: That is, nouns (e.g., FOREST) are associated with the semantic roles that they frequently instantiate (i.e., locale), and comprehension is facilitated when the given noun performs its typical role (e.g., FOREST BIRD). If one assumes that relational roles activate their complement—e.g., locale activates object — then integrative priming could occur prospectively (a.k.a. prelexically), in that the prime pre-activates the target before the target's actual presentation. By this model integrative priming occurs because the prime word (FOREST) activates its typical role (locale), which in turn activates its complementary role (object), which then activates a set of typical fillers of that role (e.g., BIRD, STREAM, etc.). Lexical decisions are facilitated for target words that are typical of the complementary role. Alternatively, integrative priming could occur retrospectively (a.k.a. postlexically), in that the prime affects the target only after the target's presentation. By this model, the prime activates its typical role and its complementary role, and then one retrospectively evaluates whether the target could plausibly perform that complementary role (e.g., whether a BIRD can have a location). Thus, the critical difference between the prospective and retrospective variants of the model arises at the point when the complementary role concept is activated. 
Although little is known about role assignment in noun compounds, indirect evidence from participle-noun phrases indicates that role typicality is critical. For instance, ARRESTING COP is understood faster than ARRESTED COP, because cops more typically perform the arrester role than the arrestee role. Conversely, ARRESTED CROOK is understood faster than ARRESTING CROOK because crooks are more typically arrestees than arresters (Ferretti, Gagne, \& McRae, 2003; see also Ferretti, Kutas, \& McRae, 2007; Ferretti, McRae, \& Hatherell, 2001; McRae, SpiveyKnowlton, \& Tanenhaus, 1998). Such lexical priming has been obtained in a naming task (Ferretti et al., 2007), which is traditionally viewed as an indicator of a prospective mechanism. Sentential contexts, on the other hand, elicit lexical priming to the extent that the sentence prime predicts the target word (see Federmeier, Wlotko, De Ochoa-Dewald, \& Kutas, 2007; Schwanenflugel \& LaCount, 1988). For example, "John went to the library to check out a..." facilitates recognition of the word "book", but "John went to the store to buy a..." does not facilitate recognition of "book". In terms of integrative priming, this result raises the question of whether modifiers such as FOREST are constraining enough to elicit priming prospectively. Some modifiers (e.g., FOREST...) have a vast number of plausible complements, whereas others seem to be more constraining (e.g., RACE...). This degree of constraint may affect the likelihood and/or magnitude of integrative priming. There is a clear need for analogous studies with noun compounds to determine whether the integrative priming demonstrated here does occur prospectively. However, it should be noted that prospective and retrospective processes both operate during lexical processing (Neely \& Keefe, 1989), so any evidence of a prospective component to integrative priming would not exclude the possibility of an additional retrospective component.

The retrospective model raises a further question of how one determines whether a concept (e.g., BIRD) can plausibly perform a given role (e.g., object). Wisniewski and Murphy 
(2005) found that the time required to comprehend an integrative noun compound was predicted by the plausibility of its referent. Critically, though, researchers disagree about what plausibility is (e.g., Gagné \& Spalding, 2006; Murphy \& Wisniewski, 2006; see also Costello \& Keane, 2000; Jones et al., 2008). Connell and Keane (2004), who tested the common assumption that something is plausible if it is consistent with prior knowledge, concluded that "a highly plausible scenario is one that fits prior knowledge (a) with many different sources of corroboration, (b) without complex explanation, and (c) with minimal conjecture" (2006, p. 117; see also Murphy \& Wisniewski, 2006). Although Connell and Keane investigated the plausibility of sentence pairs, their conclusions nonetheless may provide a useful framework for future investigation into the plausibility of noun compounds.

To complicate matters further, plausibility is practically similar to familiarityWisniewski and Murphy (2005) found a correlation of $\geq .90$ - but they are conceptually distinct constructs (Murphy \& Wisniewski, 2006). Whereas plausibility reflects the ease with which one can imagine the referent of the combination, familiarity refers to its frequency of actual occurrence. For example, OFFICE PLANT and PRISON PLANT may be equally plausible, but for most readers the former is more familiar. Our experiments have shown that familiarity is not necessary for integrative priming to occur, but in Experiment 4 familiarity did modulate the magnitude of integrative priming. Specifically, familiar compounds (e.g., OFFICE PLANT) exhibited less integrative priming than unfamiliar word pairs (e.g. PRISON PLANT). It may be that more familiar word pairs are indeed retrieved by compound cueing, as argued by McKoon and Ratcliff (1992), and hence are less susceptible to integrative priming. Nonetheless, the direction of this relationship between compound familiarity and integrative priming indicates that compound cueing cannot explain the occurrence of integrative priming. The compound cue model predicts 
greater priming among familiar compounds, but in Experiment 4 greater priming was found among unfamiliar compounds.

\section{Conclusion}

To conclude, we have shown across several experiments that relational integration facilitates lexical processing. Words are understood more quickly if they can be integrated easily with the preceding word. Moreover, the prevalence and magnitude of this integrative priming were on a par with associative priming and semantic priming. Given that relational integration is essential to and ubiquitous in language comprehension, this integrative priming is perhaps unsurprising; perhaps more surprising is that this effect has been almost entirely overlooked for the past several decades of research on lexical priming. Integrative priming is not attributable to associative strength, semantic similarity, or compound familiarity. As such, it is not explicable via any extant model of lexical priming. We have argued that the mechanism of integrative priming will most likely be found within a role assignment model of relational integration, and we suspect that role typicality, relation plausibility, and compound familiarity will be important factors for determining whether integrative priming occurs prospectively and/or retrospectively. Clearly, much remains to be determined about integrative priming. The primary contribution of the present study has been to demonstrate its robust occurrence and its independence from other forms of lexical priming. 


\section{References}

Anaki, D. \& Henik, A. (2003). Is there a "strength effect" in automatic semantic priming? Memory \& Cognition, 31, 262-272.

Anderson, J. R. (1983). A spreading activation theory of memory. Journal of Verbal Learning and Verbal Behavior, 22, 261-265.

Bassok, M., \& Medin, D. L. (1997). Birds of a feather flock together: Similarity judgments with semantically rich stimuli. Journal of Memory and Language, 36, 311-336.

Becker, C. A. (1980). Semantic context effects in visual word recognition: An analysis of semantic strategies. Memory \& Cognition, 8, 493-512.

Becker, S., Moscovitch, M., Behrmann, M., \& Joordens, S. (1997). Long-term semantic priming: A computational account and empirical evidence. Journal of Experimental Psychology: Learning, Memory, and Cognition, 23, 1059-1082.

Bodner, G. E. \& Masson, M. E. J. (2001). Prime validity affects masked repetition priming: Evidence for an episodic resource account of priming. Journal of Memory and Language, 45, 616-647.

Bodner, G. E. \& Masson, M. E. J. (2003). Beyond spreading activation: An influence of relatedness proportion on masked semantic priming. Psychonomic Bulletin \& Review, 10, 645-652.

Chwilla, D. J., Hagoort, P. \& Brown, C. E. (1998). The mechanism underlying backward priming in a lexical decision task: Spreading activation versus semantic matching. Quarterly Journal of Experimental Psychology, 51A, 531-560.

Clark, H. H. (1983). Making sense of nonce sense. In G. B. Flores d'Arcais and R. J. Jarvella (Eds.), The Process of Language Unerstanding (pp. 297-331). New York: John Wiley. 
Clark, E. V., \& Berman, R. A. (1987). Types of linguistic knowledge: Interpreting and producing compound nouns. Journal of Child Language, 14, 547-567.

Cohen, B., \& Murphy, G. L. (1984). Models of concepts. Cognitive Science, 8, 27-58.

Collins, A. M. \& Loftus, E. F. (1975). A spreading activation theory of semantic processing. Psychological Review, 82, 407-428.

Connell, L. \& Keane, M. T. (2004). What plausibly affects plausibility? Concept coherence and distributional word coherence as factors influencing plausibility judgments. Memory \& Cognition, 32, 185-197.

Connell, L. \& Keane, M. T. (2006). A model of plausibility. Cognitive Science, 30, 95-120.

Coolen, R., van Jaarsveld, H. J. \& Schreuder, R. (1991). The interpretation of isolated novel nominal compounds. Memory \& Cognition, 19, 341-352.

Costello, F. J. \& Keane, M. T. (2000). Efficient creativity: Constraint-guided conceptual combination. Cognitive Science, 24, 299-349.

de Groot, A. M. B. (1984). Primed lexical decision: Combined effects of the proportion of related prime-target pairs and the stimulus-onset asynchrony of prime and target. The Quarterly Journal of Experimental Psychology, 36A, 253-280.

de Groot, A. M. B. (1985). Word-context effects in word naming and lexical decision. Quarterly Journal of Experimental Psychology, 37A, 281-297.

de Mornay Davies, P. (1998). Automatic semantic priming: The contribution of lexical- and semantic-level processes. European Journal of Cognitive Psychology, 10, 389-412.

den Heyer, K., Briand, K. \& Smith, L. (1985). Automatic and strategic effects in semantic priming: An examination of Becker's verification model. Memory \& Cognition, 13, 228232. 
Devereux, B., \& Costello, F. J. (2005). Investigating the relations used in conceptual combination. Artificial Intelligence Review, 24, 489-515.

Downing, P. (1977). On the creation and use of English compound nouns. Language, 53, 810842.

Dosher, B. A., \& Rosedale, G. (1989). Integrated retrieval cues as a mechanism for priming in retrieval from memory. Journal of Experimental Psychology: General, 118, 191-211.

Doumas, L. A. A., Hummel, J. E., \& Sandhofer, C. M. (2008). A theory of the discovery and predication of relational concepts. Psychological Review, 115, 1-43.

Dowty, D. (1990). Thematic proto-roles and argument selection. Language, 67, 547-619.

Estes, Z. (2003a). A tale of two similarities: Comparison and integration in conceptual combination. Cognitive Science, 27, 911-921.

Estes, Z. (2003b). Attributive and relational processes in nominal combination. Journal of Memory and Language, 48, 304-319.

Estes, Z., \& Jones, L. L. (2006). Priming via relational similarity: A COPPER HORSE is faster when seen through a GLASS EYE. Journal of Memory and Language, 55, 89-101.

Estes, Z., \& Jones, L. L. (2008). Relational processing in conceptual combination and analogy. Behavioral and Brain Sciences, 31, 385-386.

Federmeier, K. D., Wlotko, E. W., De Ochoa-Dewald, E., \& Kutas, M. (2007). Multiple effects of sentential constraint on word processing. Brain Research, 1146, 75-84.

Fedorenko, E., Gibson, E., \& Rohde, D. (2007). The nature of working memory in linguistic, arithmetic and spatial integration processes. Journal of Memory and Language, 56, 246269. 
Ferretti, T. R., Gagne, C. L., \& McRae, K. (2003). Thematic role focusing by participle inflections: Evidence from conceptual combination. Journal of Experimental Psychology: Learning, Memory, and Cognition, 29, 118-126.

Ferretti, T. R., Kutas, M., \& McRae, K. (2007). Verb aspect and the activation of event knowledge. Journal of Experimental Psychology: Learning, Memory, and Cognition, 33, 182-196.

Ferretti, T. R., McRae, K., \& Hatherell, A. (2001). Integrating verbs, situation schemes, and thematic role concepts. Journal of Memory and Language, 44, 516-547.

Fischler, I. (1977). Semantic facilitation without association in a lexical decision task. Memory \& Cognition, 5, 335-339.

Fischler, I. \& Bloom, P. A. (1979). Automatic and attentional processes in the effects of sentence contexts on word recognition. Journal of Verbal Learning \& Verbal Behavior, 18, 1-20.

Forster, K. I. (1981). Priming and the effects of sentence and lexical contexts on naming time: Evidence for autonomous lexical processing. The Quarterly Journal of Experimental Psychology, 33A, 465-495.

Gagné, C. L. (2000). Relation-based combinations versus property-based combinations: A test of the CARIN theory and the dual-process theory of conceptual combination. Journal of Memory and Language, 42, 365-389.

Gagné, C. L., \& Murphy, G. L. (1996). Influence of discourse context on feature availability in conceptual combination. Discourse Processes, 22, 79-101.

Gagné, C. L., \& Shoben, E. (1997). The influence of thematic relations on the comprehension of modifier-noun combinations. Journal of Experimental Psychology: Learning, Memory, and Cognition, 23, 71-87. 
Gagné, C. L., \& Spalding, T. L. (2006). Relation availability was not confounded with familiarity or plausibility in Gagné and Shoben (1997): Comment on Wisniewski and Murphy (2005). Journal of Experimental Psychology: Learning, Memory, and Cognition, 32, 1431-1437.

Garrod, S. \& Terras, M. (2000). The contribution of lexical and situational knowledge to resolving discourse roles: Bonding and resolution. Journal of Memory and Language, 42, 526-544.

Gildea, D. \& Jurafsky, D. (2002). Automatic labeling of semantic roles. Computational Linguistics, 28, 245-288.

Glucksberg, S., \& Estes, Z. (2000). Feature accessibility in conceptual combination: Effects of context-induced relevance. Psychonomic Bulletin \& Review, 7, 510-515.

Haarmann, H. J., Davelaar, E. J., \& Usher, M. (2003). Individual differences in semantic shortterm memory capacity and reading comprehension. Journal of Memory and Language, 48, 320-345.

Hagoort, P., Hald, L., Bastiaansen, M., \& Petersson, K. M. (2004). Integration of word meaning and world knowledge in language comprehension. Science, 304, 438-441.

Henik, A., Friedrich, F. J., Tzelgov, J., \& Tramer, S. (1994). Capacity demands of automatic processes in semantic priming. Memory \& Cognition, 22, 157-168.

Hess, D. J., Foss, D. J., \& Carroll, P. (1995). Effects of global and local context on lexical processing during language comprehension. Journal of Experimental Psychology: General, 124, 62-82.

Hodgson, J. M. (1991). Information constraints on pre-lexical priming. Language and Cognitive Processes, 6, 169-205. 
Hummel, J. E., \& Holyoak, K. J. (1997). Distributed representations of structure: A theory of analogical access and mapping. Psychological Review, 104, 427-466.

Hummel, J. E., \& Holyoak, K. J. (2003). A symbolic connectionist theory of relational inference and generalization. Psychological Review, 110, 220-264.

Hutchison, K. A. (2002). The effect of asymmetrical association on positive and negative semantic priming. Memory \& Cognition, 30, 1263-1276.

Hutchison, K. A. (2003). Is semantic priming due to association strength or feature overlap? A microanalytic review. Psychonomic Bulletin \& Review, 10, 785-813.

Hutchison, K. A. (2007). Attentional control and the relatedness proportion effect in semantic priming. Journal of Experimental Psychology: Learning, Memory, and Cognition, 33, 645-662.

Hutchison, K. A., Balota, D. A., Cortese, M. J., \& Watson, J. M. (2008). Predicting semantic priming at the item level. The Quarterly Journal of Experimental Psychology, 61, 10361066.

Hutchison, K. A., Neely, J. H. \& Johnson, J. D. (2001). With great expectations, can two “wrongs" prime a "right”? Journal of Experimental Psychology: Learning, Memory, and Cognition, 27, 1451-1463.

Jarema, G., Busson, C., Nikolova, R., Tsapkini, K., \& Libben, G. (1999). Processing compounds: A cross-linguistic study. Brain and Language, 68, 362-369.

Jones, L. L., Estes, Z., \& Marsh, R. L. (2008). An asymmetric effect of relational integration on recognition memory. The Quarterly Journal of Experimental Psychology, 61, 1169-1176.

Jones, M. \& Love, B. C. (2007). The role of roles in determining similarity. Cognitive Psychology, 55, 196-231. 
Kay, P., \& Zimmer, K. (1976). On the semantics of compounds and genitives in English. In R. Underhill (Ed.), Sixth California Linguistics Association Conference Proceedings. San Diego State University.

Kiefer, M., Ahlegian, M., \& Spitzer, M. (2005). Working memory capacity, indirect semantic priming, and Stroop interference: Pattern of interindividual prefrontal performance differences in healthy volunteers. Neuropsychology, 19, 332-344.

Kucera, H., \& Francis, W. N. (1967). Computational Analysis of Present-Day American English. Providence, R. I.: Brown University Press.

Landauer, T. K. \& Dumais, S. T. (1997). A solution to Plato's problem: The latent semantic analysis theory of acquisition, induction, and representation of knowledge. Psychological Review, 104, 211-240.

Lees, R. B. (1963). The Grammar of English Nominalizations. Bloomington, IN: Indiana University Press.

Levi, J. N. (1978). The Syntax and Semantics of Complex Nominals. New York: Academic Press. Libben, G., Gibson, M., Yoon, Y. B., \& Sandra, D. (2003). Compound fracture: The role of semantic transparency and morphological headedness. Brain and Language, 84, 50-64.

Lin, E. L., \& Murphy, G. L. (2001). Thematic relations in adults' concepts. Journal of Experimental Psychology: General, 130, 3-28.

Lucas, M. (2000). Semantic priming without association: A meta-analytic review. Psychonomic Bulletin \& Review, 7, 618-630.

Lupker, S. J. (1984). Semantic priming without association: A second look. Journal of Verbal Learning and Verbal Behavior, 23, 709-733. 
Maguire, P., Devereux, B., Costello, F., \& Cater, A. (2007). A reanalysis of the CARIN theory of conceptual combination. Journal of Experimental Psychology: Learning, Memory, and Cognition, 33, 811-821.

Masson, M. E. J. (1995). A distributed memory model of semantic priming. Journal of Experimental Psychology: Learning, Memory, and Cognition, 21, 3-23.

McKoon, G., \& Ratcliff, R. (1992). Spreading activation versus compound-cue accounts of priming: Mediated priming revisited. Journal of Experimental Psychology: Learning, Memory, and Cognition, 18, 1155-1172.

McKoon, G. \& Ratcliff, R. (1995). Conceptual combinations and relational contexts in free association and in priming in lexical decision and naming. Psychonomic Bulletin \& Review, 2, 527-533.

McNamara, T. P. (1992a). Priming and constraints it places on theories of memory and retrieval. Psychological Review, 99, 650-662.

McNamara, T. P. (1992b). Theories of priming: I. Associative distance and lag. Journal of Experimental Psychology: Learning, Memory, and Cognition, 18, 1173-1190.

McNamara, T. P. (1994). Theories of priming: II. Types of primes. Journal of Experimental Psychology: Learning, Memory, and Cognition, 20, 507-520.

McNamara, T. P. (2005). Semantic priming: Perspectives from memory and word recognition. New York: Psychology Press.

McRae, K. \& Boisvert, S. (1998). Automatic semantic similarity priming. Journal of Experimental Psychology: Learning, Memory, and Cognition, 24, 558-572.

McRae, K., de Sa, V. R., \& Seidenberg, M. S. (1997). On the nature and scope of featural representations of word meaning. Journal of Experimental Psychology: General, 126, 99130. 
McRae, K., Spivey-Knowlton, M. J., \& Tanenhaus, M. K. (1998). Modeling the influence of thematic fit (and other constraints) in on-line sentence comprehension. Journal of Memory and Language, 38, 283-312.

Meyer, D. E. \& Schvaneveldt, R. W. (1971). Facilitation in recognizing pairs of words: Evidence of a dependence between retrieval operations. Journal of Experimental Psychology, 90, 227-234.

Meyer, D. E., Schvaneveldt, R. W. \& Ruddy, M. G. (1975). Loci of contextual effects in visual word recognition. In P. M. A. Rabbitt (Ed.), Attention and Performance V (pp. 98-118). New York: Academic Press.

Moors, A. \& De Houwer, J. (2006). Automaticity: A theoretical and conceptual analysis. Psychological Bulletin, 132, 297-326.

Moss, H. E., Ostrin, R. K., Tyler, L. K. \& Marslen-Wilson, W. D. (1995). Accessing different types of lexical semantic information: Evidence from priming. Journal of Experimental Psychology: Learning, Memory, and Cognition, 21, 863-883.

Murphy, G. L. (1988). Comprehending complex concepts. Cognitive Science, 12, 529-562.

Murphy, G. L. (2001). Causes of taxonomic sorting by adults: A test of the thematic-totaxonomic shift. Psychonomic Bulletin \& Review, 8, 834-839.

Murphy, G. L. (2002). The big book of concepts. Cambridge, MA: MIT Press.

Murphy, G. L. \& Wisniewski, E. J. (2006). Familiarity and plausibility in conceptual combination: Reply to Gagné and Spalding (2006). Journal of Experimental Psychology: Learning, Memory, and Cognition, 32, 1438-1442.

Nation, K., Adams, J. W., Bowyer-Crane, C. A., \& Snowling, M. J. (1999). Working memory deficits in poor comprehenders reflect underlying language impairments. Journal of Experimental Child Psychology, 73, 139-158. 
Nation, K., \& Snowling, M. J. (1999). Developmental differences in sensitivity to semantic relations among good and poor comprehenders: Evidence from semantic priming. Cognition, 70, B1-B13.

Neely, J. H. (1977). Semantic priming and retrieval from lexical memory: Roles of inhibitionless spreading activation and limited-capacity attention. Journal of Experimental Psychology: General, 106, 226-254.

Neely, J. H. (1991). Semantic priming effects in visual word recognition: A selective review of current findings and theories. In D. Besner \& G. W. Humphreys (Eds.), Basic Processes in Reading: Visual Word Recognition (pp. 264-336). Hillsdale, NJ: Erlbaum.

Neely, J. H. \& Keefe, D. E. (1989). Semantic context effects on visual word processing: A hybrid prospective-retrospective processing theory. In G. H. Bower (Ed.), The psychology of learning and motivation: Advances in research and theory (Vol. 24, pp. 207-248). New York: Academic Press.

Neely, J. H., Keefe, D. E. \& Ross, K. L. (1989). Semantic priming in the lexical decision task: Roles of prospective prime-generated expectancies and retrospective semantic matching. Journal of Experimental Psychology: Learning, Memory, and Cognition, 15, 1003-1019.

Nelson, D. L., McEvoy, C. L. \& Schreiber, T. A. (2004). The University of South Florida free association, rhyme, and word fragment norms. Behavior Research Methods, Instruments, and Computers, 36, 402-407.

Perea, M. \& Rosa, E. (2002). Does the proportion of associatively related pairs modulate the associative priming effect at very brief stimulus-onset asynchronies? Acta Psychologica, 110, 103-124. 
Plaut, D. C. \& Booth, J. R. (2000). Individual and developmental differences in semantic priming: Empirical and computacional support for a single-mechanism account of lexical processing. Psychological Review, 107, 786-823.

Posner, M. I. \& Snyder, C. R. (1975). Attention and cognitive control. In R. L. Solso (Ed.), Information Processing and Cognition (pp. 55-85). Hillsdale, NJ: Erlbaum.

Ratcliff, R. \& McKoon, G. (1988). A retrieval theory of priming. Psychological Review, 95, 385408.

Ryder, M. E. (1994). Ordered Chaos: The Interpretation of English Noun-Noun Compounds. Berkeley, CA: University of California Press.

Schwanenflugel, P. J., \& LaCount, K. L. (1988). Semantic relatedness and the scope of facilitation for upcoming words in sentences. Journal of Experimental Psychology: Learning, Memory, and Cognition, 14, 344-354.

Seidenberg, M. S., Waters, G. S., Sanders, M. \& Langer, P. (1984). Pre- and postlexical loci of contextual effects on word recognition. Memory \& Cognition, 12, 315-328.

Shelton, J. R., \& Martin, R. C. (1992). How semantic is automatic semantic priming? Journal of Experimental Psychology: Learning, Memory, and Cognition, 18, 1191-1210.

Simmons, S., \& Estes, Z. (2008). Individual differences in the perception of similarity and difference. Cognition, 108, 781-795.

Smith, E. E., Osherson, D. N., Rips, L. J., \& Keane, M. (1988). Combining prototypes: A selective modification model. Cognitive Science: A Multidisciplinary Journal, 12, 485527.

Solomon, E. S., \& Pearlmutter, N. J. (2004). Semantic integration and syntactic planning in language production. Cognitive Psychology, 49, 1-46. 
Springer, K., \& Murphy, G. L. (1992). Feature availability in conceptual combination.

Psychological Science, 3, 111-117.

Stolz, J. A., Besner, D., \& Carr, T. H. (2005). Implications of measures of reliability for theories of priming: Activity in semantic memory is inherently noisy and uncoordinated. Visual Cognition, 12, 284-336.

Stolz, J. A., \& Neely, J. H. (1995). When degradation does and does not enhance semantic context effects in word recognition. Journal of Experimental Psychology: Learning, Memory, and Cognition, 21, 596-611.

Storms, G. \& Wisniewski, E. J. (2005). Does the order of head noun and modifier explain response times in conceptual combination? Memory \& Cognition, 33, 852-861.

Swinney, D., Love, T., Walenski, M., Smith, E. E. (2007). Conceptual combination during sentence comprehension: Evidence for compositional processes. Psychological Science, $18,397-400$.

Thompson-Schill, S. L., Kurtz, K. J. \& Gabrieli, J. D. E. (1998). Effects of semantic and associative relatedness on automatic priming. Journal of Memory and Language, 38, 440458.

Tweedy, J. R., Lapinski, R. H. \& Schvaneveldt, R. W. (1977). Semantic-context effects on word recognition: Influence of varying the proportion of items presented in an appropriate context. Memory \& Cognition, 5, 84-89.

Warren, B. (1978). Semantic Patterns of Noun-Noun Compounds. Goteborg, Sweden: Acta Universitatis Gothoburgensis.

Whittlesea, B. W., \& Jacoby, L. L. (1990). Interaction of prime repetition with visual degradation: Is priming a retrieval phenomenon? Journal of Memory and Language, 29, 546-565. 
Williams, J. N. (1996). Is automatic priming semantic? European Journal of Cognitive Psychology, 8, 113-161.

Wilkenfeld, M. J., \& Ward, T. B. (2000). Similarity and emergence in conceptual combination. Journal of Memory \& Language, 45, 21-38.

Wisniewski, E. J. (1996). Construal and similarity in conceptual combination. Journal of Memory and Language, 35, 434-453.

Wisniewski, E. J. (1997). When concepts combine. Psychonomic Bulletin \& Review, 4, 167-183.

Wisniewski, E. J., \& Bassok, M. (1999). What makes a man similar to a tie? Stimulus compatibility with comparison and integration. Cognitive Psychology, 39, 208-238.

Wisniewski, E. J., \& Love, B. C. (1998). Relations versus properties in conceptual combination. Journal of Memory and Language, 38, 177-202.

Wisniewski, E. J., \& Murphy, G. L. (2005). Frequency of relation type as a determinant of conceptual combination: A reanalysis. Journal of Experimental Psychology: Learning, Memory, and Cognition, 31, 169-174.

Woltz, D. J., \& Was, C. A. (2007). Available but unattended conceptual information in working memory: Temporarily active semantic content or persistent memory for prior operations? Journal of Experimental Psychology: Learning, Memory, and Cognition, 33, 155-168. 


\section{Appendix A}

Stimuli, Experiments 1, 2, and 3.

\begin{tabular}{|c|c|c|c|}
\hline \multirow[b]{2}{*}{ Target } & \multicolumn{3}{|c|}{ Prime } \\
\hline & Integrative & Associative & Semantic \\
\hline book* & travel & author & article \\
\hline cake* & lemon & icing & muffin \\
\hline $\operatorname{can}^{*}$ & soup & opener & jug \\
\hline candle & birthday & wick & flashlight \\
\hline car* & race & tire & motorcycle \\
\hline church* & town & priest & convent \\
\hline diamond & necklace & gem & pearl \\
\hline doctor* & horse & patient & sick \\
\hline $\operatorname{dog} *$ & apartment & bone & fox \\
\hline dress* & velvet & gown & lady \\
\hline fish* & ocean & net & lobster \\
\hline foot* & monkey & ankle & paw \\
\hline garden & herb & hoe & lawn \\
\hline ghost & halloween & ghoul & vampire \\
\hline grape* & jelly & raisin & cherry \\
\hline heart & donor & valentine & liver \\
\hline horn & brass & bugle & clarinet \\
\hline horse* & parade & mare & ox \\
\hline house* & beach & mortgage & palace \\
\hline idea & thesis & notion & insight \\
\hline land* & border & acre & field \\
\hline leaf & maple & rake & branch \\
\hline lie & government & fib & fact \\
\hline love & puppy & affection & trust \\
\hline meat* & deer & butcher & vegetable \\
\hline milk* & strawberry & calcium & juice \\
\hline money* & copper & budget & credit \\
\hline mouse* & farm & trap & chipmunk \\
\hline pants* & linen & belt & blouse \\
\hline paper* & rice & pen & envelope \\
\hline piano* & concert & keyboard & harp \\
\hline pipe* & steel & plumber & tube \\
\hline plane* & corporate & pilot & rocket \\
\hline rabbit & trick & carrot & mole \\
\hline rain* & summer & umbrella & tornado \\
\hline
\end{tabular}

Note. * Item used in Experiment 3. 


\section{Appendix A continued}

Stimuli, Experiments 1, 2, and 3, continued.

\section{Prime}

\begin{tabular}{llll}
\cline { 2 - 4 } Target & Integrative & Associative & Semantic \\
\hline school & law & campus & office \\
sleep & airplane & nap & fatigue \\
snake* & jungle & cobra & crocodile \\
snow & mountain & ski & wind \\
soap* & bathroom & lather & shampoo \\
sport* & winter & athlete & tennis \\
teeth* & gold & dentist & tongue \\
toy* & plastic & yo-yo & game \\
wine* & box & cork & gin \\
wood & fireplace & termite & coal \\
\hline
\end{tabular}

Note. ${ }^{*}$ Item used in Experiment 3. 


\section{Appendix B}

Stimuli, Experiment 4.

\section{Prime}

\begin{tabular}{|c|c|c|}
\hline Target & Integrative & Unrelated \\
\hline beer & celebration & stairway \\
\hline book & travel & pillow \\
\hline car & company & celebration \\
\hline cow & stable & winter \\
\hline dance & square & company \\
\hline doctor & horse & travel \\
\hline $\operatorname{dog}$ & guide & square \\
\hline fall & stairway & plastic \\
\hline fence & chain & mushroom \\
\hline fight & pillow & horse \\
\hline flower & lapel & plug \\
\hline food & pub & corporate \\
\hline hat & plastic & glass \\
\hline house & glass & guide \\
\hline island & monkey & chain \\
\hline light & plug & theory \\
\hline math & theory & gold \\
\hline money & copper & lapel \\
\hline mouse & farm & lecture \\
\hline paper & rice & beach \\
\hline party & pool & farm \\
\hline plane & corporate & stable \\
\hline run & beach & box \\
\hline sleep & lecture & monkey \\
\hline smoke & industry & rice \\
\hline soup & mushroom & pool \\
\hline sport & winter & gear \\
\hline stick & gear & pub \\
\hline teeth & gold & industry \\
\hline wine & box & copper \\
\hline
\end{tabular}




\section{Author Note}

The authors contributed equally to this research. Portions of this research were presented at the $47^{\text {th }}$ Annual Meeting of the Psychonomic Society (Houston, TX).

Zachary Estes, Department of Psychology, University of Warwick, Coventry CV4 7AL, United Kingdom, E-mail: z.estes@warwick.ac.uk.

Lara L. Jones, Department of Psychology, Francis Marion University, P.O. Box 100547 Florence, SC, 29505, United States, Email: ljones@fmarion.edu. 


\section{Footnotes}

1. The number and specificity of such integrative relations have been the subject of much debate. Many researchers have explicitly claimed or tacitly assumed that a small set of general relations (e.g., have, make, etc.) is sufficient to characterize all or most instances of relational integration (Coolen, van Jaarsveld, \& Schreuder, 1991; Gagné, 2000; Lees, 1963; Levi, 1978; Ryder, 1994; Warren, 1978). However, these general relations have been criticized for being too vague to adequately describe their actual cognitive instantiations (Clark, 1983; Devereux \& Costello, 2005; Downing, 1977; Estes, 2003b; Estes \& Jones, 2006; Kay \& Zimmer, 1976; Maguire, Devereux, Costello, \& Cater, 2007; Murphy, 1988, 2002; Murphy \& Wisniewski, 2006). For example, although Levi classified both NUT BREAD and FRUIT TREE as exemplars of a general have relation (i.e., Y has $\mathrm{X}$ ), the former instantiates more specifically a containment relation (i.e., BREAD that contains NUTS) whereas the latter instantiates a seemingly different production relation (i.e., TREE that produces FRUIT). Although the evidence favors more specific integrative relations, their specificity makes no difference to the present investigation.

2. Historically, many researchers have used the terms "strategic" and "automatic" instead of "controlled" and "uncontrolled," respectively. However, "automatic" has been used to refer to any or all of several properties (e.g., uncontrolled, unintentional, fast, effortless, efficient), and hence its use conflates properties that in principle are independent (see Moors \& De Houwer, 2006). To circumvent this conflation, we heed Moors and De Houwer's suggestion to refer more precisely to the specific property under investigation.

3. Of course, because it rests on a null difference between the high- and low-RP conditions, this conclusion is necessarily tentative. However, it should also be noted that the present experiments did employ a standard method (i.e., LDT) with large samples, and did yield a 
highly significant effect of integrative priming. So if there is any effect of RP on integrative priming, it would appear to be rather subtle.

4. Models vary dramatically in the number and specificity of semantic roles. Take for example the verb sell, which is a relational concept that entails two roles. These roles could be represented abstractly via proto-roles like agent and patient (Dowty, 1991) or quite specifically as jeweler and jewel wearer (see Gildea \& Jurafsky, 2002). An emerging consensus is that role representations are of more intermediate specificity (e.g., Ferretti et al., 2001; Gildea \& Jurafsky, 2002; Jones \& Love, 2007), in this example perhaps like salesperson and purchaser. 
Table 1. Integration ratings, association values, and similarity ratings of the stimuli used in Experiments 1 and 2.

\begin{tabular}{|c|c|c|c|c|c|c|c|c|}
\hline \multirow[b]{3}{*}{ Prime-type } & & & \multicolumn{4}{|c|}{ Association } & & \\
\hline & \multicolumn{2}{|c|}{ Integration } & \multicolumn{2}{|c|}{ Forward } & \multicolumn{2}{|c|}{ Backward } & \multicolumn{2}{|c|}{ Similarity } \\
\hline & $\mathbf{M}$ & SD & $\mathbf{M}$ & SD & $\mathbf{M}$ & SD & $\mathbf{M}$ & SD \\
\hline Integrative & 5.41 & 0.85 & 0.02 & 0.03 & 0.00 & 0.01 & 2.14 & 0.87 \\
\hline Associative & 3.96 & 0.65 & 0.48 & 0.20 & 0.02 & 0.02 & 3.71 & 1.50 \\
\hline Semantic & 3.00 & 0.74 & 0.02 & 0.02 & 0.01 & 0.02 & 4.68 & 0.77 \\
\hline
\end{tabular}

Note. Integration scale $=1$ (not linked) to 7 (tightly linked). Forward and Backward Association values are free association probabilities from Nelson, McEvoy, and Schreiber (1998). Similarity scale $=1$ (not at all) to 7 (very) 
Table 2. Response times (ms) and accuracy rates (proportion correct) across SOAs, Experiments 1 and 2.

\begin{tabular}{|c|c|c|c|c|c|c|c|c|c|c|c|c|}
\hline \multirow[b]{3}{*}{ Exp't } & \multirow[b]{3}{*}{ Prime-type } & \multirow[b]{3}{*}{ Measure } & \multicolumn{10}{|c|}{ SOA } \\
\hline & & & \multicolumn{2}{|c|}{100} & \multicolumn{2}{|c|}{500} & \multicolumn{2}{|c|}{1500} & \multicolumn{2}{|c|}{2000} & \multicolumn{2}{|c|}{2500} \\
\hline & & & $\mathbf{M}$ & SE & $\mathbf{M}$ & SE & $\mathbf{M}$ & SE & $\mathbf{M}$ & SE & $\mathbf{M}$ & SE \\
\hline \multirow[t]{6}{*}{1} & Baseline & RT & & & 585 & 12 & & & 644 & 26 & & \\
\hline & & Accuracy & & & 0.98 & 0.005 & & & 0.98 & 0.006 & & \\
\hline & Associative & RT & & & 543 & 15 & & & 580 & 18 & & \\
\hline & & Accuracy & & & 0.99 & 0.004 & & & 0.99 & 0.004 & & \\
\hline & Integrative & RT & & & 543 & 14 & & & 622 & 25 & & \\
\hline & & Accuracy & & & 0.98 & 0.005 & & & 0.98 & 0.007 & & \\
\hline \multirow[t]{6}{*}{2} & Baseline & RT & 631 & 15 & 638 & 18 & 663 & 20 & & & 667 & 18 \\
\hline & & Accuracy & 0.99 & 0.004 & 0.99 & 0.005 & 0.99 & 0.004 & & & 0.99 & 0.004 \\
\hline & Semantic & RT & 613 & 13 & 595 & 22 & 627 & 19 & & & 652 & 18 \\
\hline & & Accuracy & 0.99 & 0.005 & 0.99 & 0.003 & 0.99 & 0.003 & & & 0.99 & 0.004 \\
\hline & Integrative & RT & 611 & 14 & 589 & 21 & 639 & 22 & & & 644 & 14 \\
\hline & & Accuracy & 0.98 & 0.005 & 0.98 & 0.005 & 0.99 & 0.003 & & & 0.99 & 0.004 \\
\hline
\end{tabular}


Table 3. Response times (ms) and accuracy rates (proportion correct) across Experiments 3A, $3 \mathrm{~B}$, and 4.

\begin{tabular}{|c|c|c|c|c|c|c|}
\hline \multirow[b]{2}{*}{ Exp't } & \multirow[b]{2}{*}{$\mathbf{R P}$} & \multirow[b]{2}{*}{ Prime-type } & \multicolumn{2}{|c|}{ RT } & \multicolumn{2}{|c|}{ Accuracy } \\
\hline & & & $\mathbf{M}$ & $\mathrm{SE}$ & $\mathbf{M}$ & SE \\
\hline \multirow[t]{4}{*}{$3 \mathrm{~A}$} & 0.20 & Baseline & 582 & 10 & 0.99 & 0.004 \\
\hline & & Integrative & 555 & 12 & 0.98 & 0.007 \\
\hline & 0.80 & Baseline & 578 & 9 & 0.99 & 0.003 \\
\hline & & Integrative & 545 & 10 & 0.99 & 0.003 \\
\hline \multirow[t]{4}{*}{$3 \mathrm{~B}$} & 0.20 & Baseline & 592 & 10 & 0.99 & 0.001 \\
\hline & & Semantic & 585 & 13 & 0.99 & 0.003 \\
\hline & 0.80 & Baseline & 584 & 12 & 0.99 & 0.004 \\
\hline & & Semantic & 552 & 13 & 0.99 & 0.004 \\
\hline \multirow[t]{4}{*}{4} & 0.20 & Baseline & 559 & 10 & 0.99 & 0.004 \\
\hline & & Integrative & 545 & 9 & 0.99 & 0.004 \\
\hline & 0.80 & Baseline & 563 & 11 & 0.99 & 0.003 \\
\hline & & Integrative & 547 & 10 & 0.99 & 0.003 \\
\hline
\end{tabular}


Table 4. Prevalence and magnitude of priming effects across experiments.

\begin{tabular}{|c|c|c|c|c|c|}
\hline Exp't & Prime-type & SOA & $\mathbf{R P}$ & Prevalence & Magnitude \\
\hline \multirow[t]{6}{*}{1} & Integrative & 500 & 1.00 & $81 \%$ & $57 \mathrm{~ms}$ \\
\hline & & 2000 & 1.00 & $68 \%$ & $56 \mathrm{~ms}$ \\
\hline & & & Total & $74 \%$ & $57 \mathrm{~ms}$ \\
\hline & Associative & 500 & 1.00 & $81 \%$ & $58 \mathrm{~ms}$ \\
\hline & & 2000 & 1.00 & $81 \%$ & $91 \mathrm{~ms}$ \\
\hline & & & Total & $81 \%$ & $74 \mathrm{~ms}$ \\
\hline \multirow[t]{10}{*}{2} & Integrative & 100 & 1.00 & $60 \%$ & $53 \mathrm{~ms}$ \\
\hline & & 500 & 1.00 & $76 \%$ & $86 \mathrm{~ms}$ \\
\hline & & 1500 & 1.00 & $60 \%$ & $73 \mathrm{~ms}$ \\
\hline & & 2500 & 1.00 & $56 \%$ & $74 \mathrm{~ms}$ \\
\hline & & & Total & $63 \%$ & $72 \mathrm{~ms}$ \\
\hline & Semantic & 100 & 1.00 & $65 \%$ & $44 \mathrm{~ms}$ \\
\hline & & 500 & 1.00 & $71 \%$ & $74 \mathrm{~ms}$ \\
\hline & & 1500 & 1.00 & $73 \%$ & $58 \mathrm{~ms}$ \\
\hline & & 2500 & 1.00 & $56 \%$ & $75 \mathrm{~ms}$ \\
\hline & & & Total & $66 \%$ & $62 \mathrm{~ms}$ \\
\hline \multirow[t]{3}{*}{$3 \mathrm{~A}$} & Integrative & 500 & 0.20 & $73 \%$ & $51 \mathrm{~ms}$ \\
\hline & & 500 & 0.80 & $71 \%$ & $58 \mathrm{~ms}$ \\
\hline & & & Total & $72 \%$ & $54 \mathrm{~ms}$ \\
\hline \multirow[t]{3}{*}{$3 \mathrm{~B}$} & Semantic & 500 & 0.20 & $56 \%$ & $51 \mathrm{~ms}$ \\
\hline & & 500 & 0.80 & $74 \%$ & $60 \mathrm{~ms}$ \\
\hline & & & Total & $65 \%$ & $56 \mathrm{~ms}$ \\
\hline \multirow[t]{3}{*}{4} & Integrative & 500 & 0.20 & $62 \%$ & $44 \mathrm{~ms}$ \\
\hline & & 500 & 0.80 & $63 \%$ & $48 \mathrm{~ms}$ \\
\hline & & & Total & $63 \%$ & $46 \mathrm{~ms}$ \\
\hline
\end{tabular}

Note. "Prevalence" is the percentage of participants who exhibited a priming effect (i.e., Baseline RT - Experimental RT >0). "Magnitude" is the mean size of the priming effect (i.e., Baseline RT - Experimental RT) among those participants who exhibited priming. 
Figure 1. Associative and integrative priming $(M \pm S E)$ as a function of SOA, Experiment 1.

"Priming" = Baseline RT - Experimental RT; positive values indicate facilitation.

- - Associative $\longrightarrow$ - Integrative

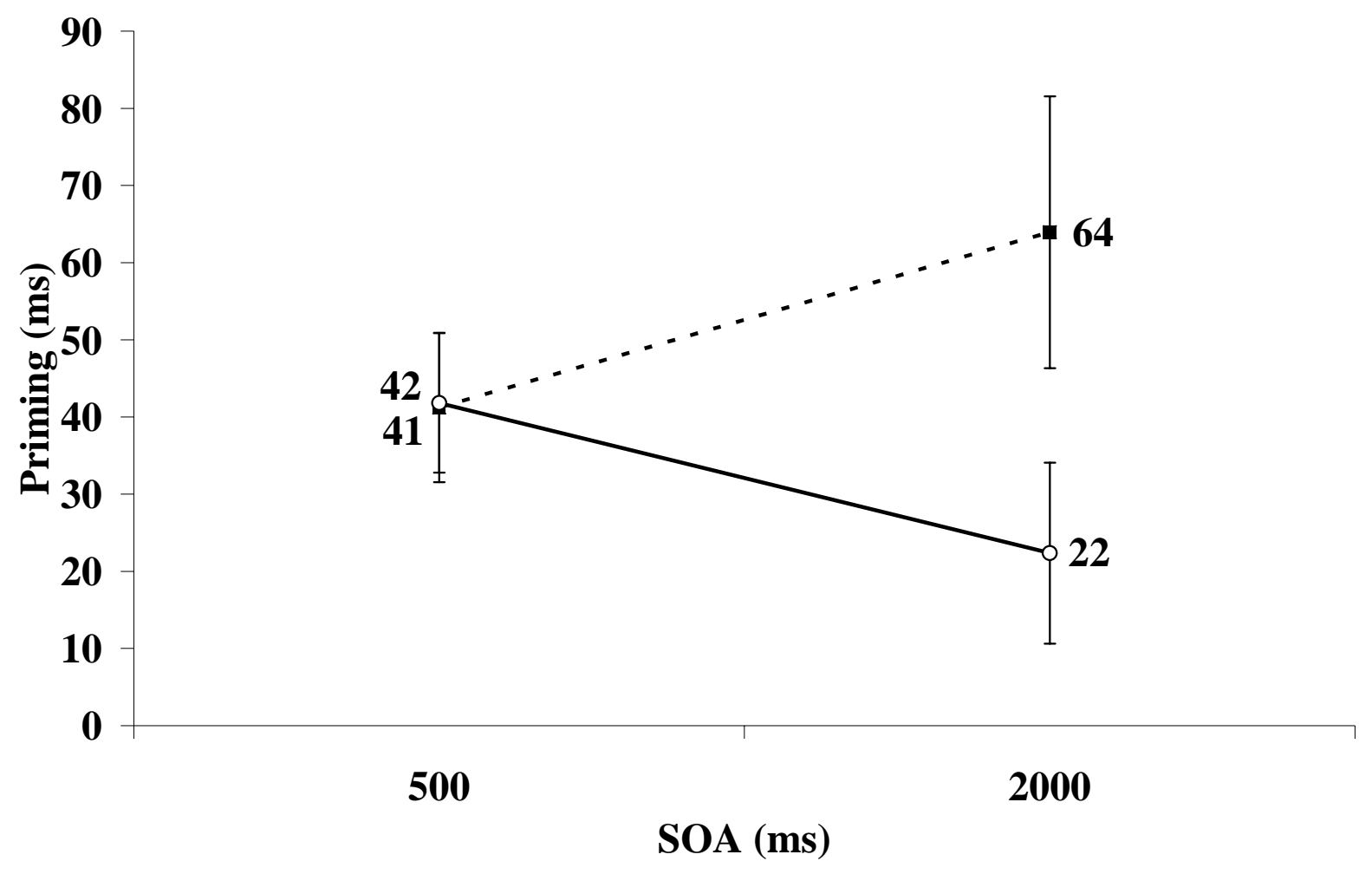


Figure 2. Semantic and integrative priming $(M \pm S E)$ as a function of SOA, Experiment 2.

"Priming" = Baseline RT - Experimental RT; positive values indicate facilitation.

$$
\text { - - Semantic ־- Integrative }
$$

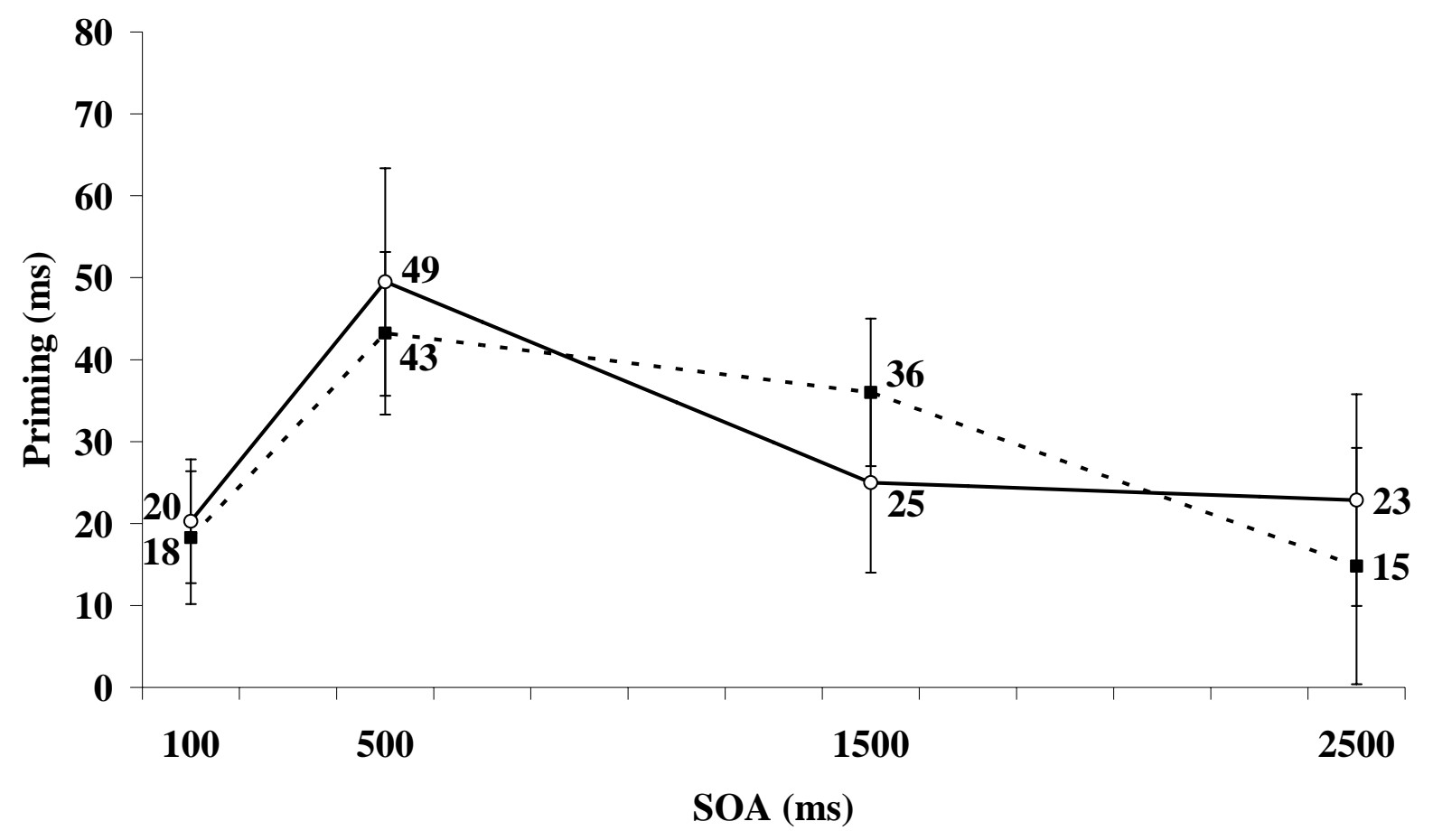


Figure 3. Integrative and semantic priming $(M \pm S E)$ as a function of RP in Experiments $3 \mathrm{~A}$ (Panel A), 3B (Panel B), and 4 (Panel C). "Priming" = Baseline RT - Experimental RT; positive values indicate facilitation. ${ }^{*} p<.05, * * p<.01, * * * p<.001$.

$$
\square \mathbf{R P}=.20 \square \mathbf{R P}=.80
$$

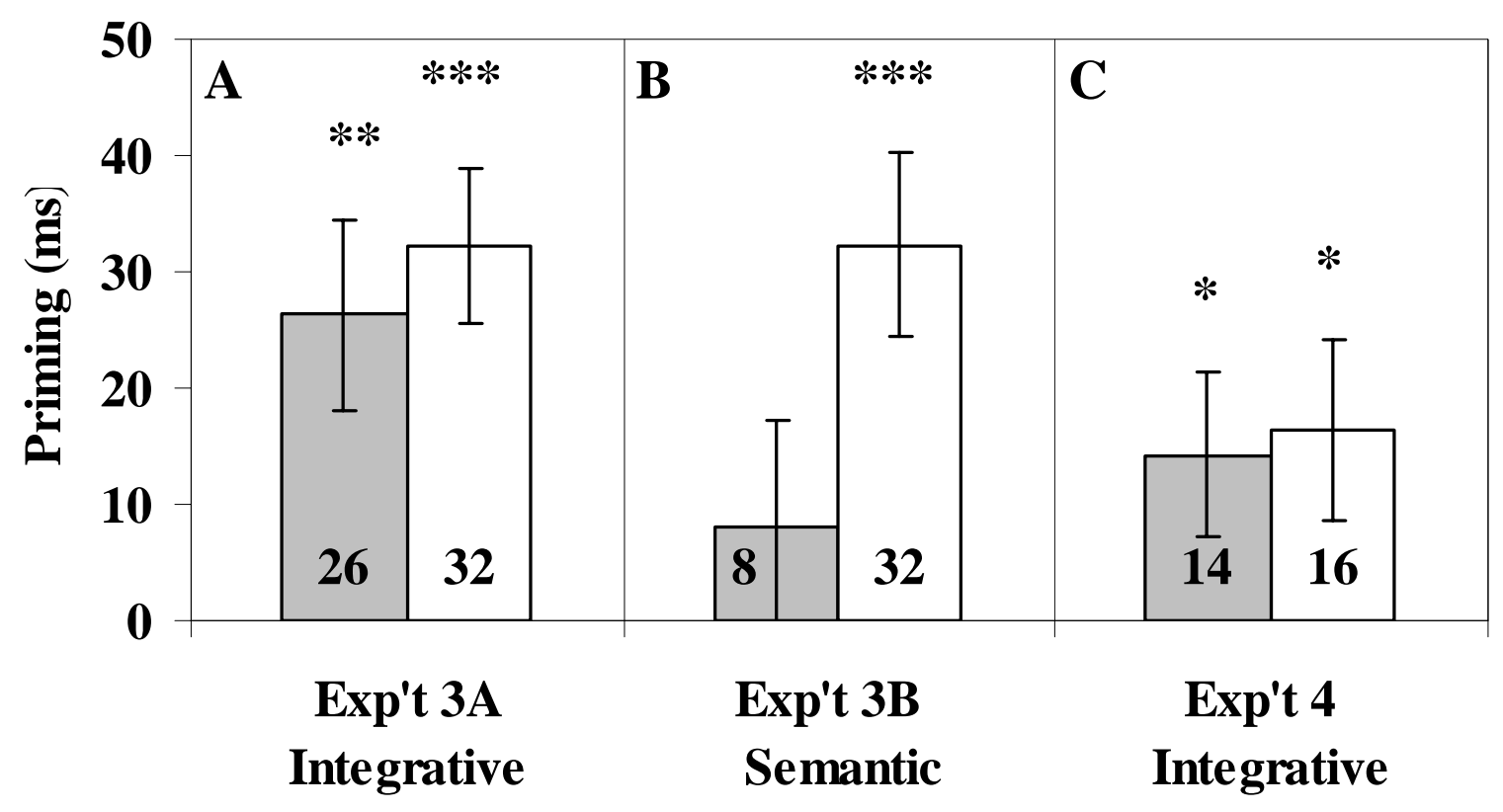

